\title{
Watermelon rinds as cost-efficient adsorbent for acridine orange: a response surface methodological approach
}

\author{
Ahmed S. El-Shafie ${ }^{1} \cdot$ Siham S. Hassan $^{1} \cdot$ Nuri Akther $^{1} \cdot$ Marwa El-Azazy $^{1}$ (D) \\ Received: 17 December 2020 / Accepted: 22 March 2021 \\ (C) The Author(s) 2021
}

\begin{abstract}
In the current investigation, watermelon rinds (WMR) have been utilized as an eco-friendly and cost-efficient adsorbent for acridine orange (AO) from contaminated water samples. Adsorption of AO onto raw (RWM) and thermally treated rinds (TTWM250 and TTWM500) has been studied. The adsorption efficiency of the three adsorbents was evaluated by measuring the \% removal $(\% R)$ of AO and the adsorption capacity $\left(q_{e}, \mathrm{mg} / \mathrm{g}\right)$. Dependent variables $\left(\% R\right.$ and $\left.q_{e}\right)$ were optimized as a function of four factors: $\mathrm{pH}$, sorbent dosage (AD), the concentration of AO (DC), and contact time (ST). Box-Behnken (BB) design has been utilized to obtain the optimum adsorption conditions. Prepared adsorbents have been characterized using scanning electron microscopy (SEM), Fourier-transform infrared (FT-IR), and Raman spectroscopies. The surface area of RWM, TTWM250, and TTWM500, as per the Brunauer-Emmett-Teller (BET) analysis, was 2.66, 2.93, and $5.03 \mathrm{~m}^{2} / \mathrm{g}$, respectively. Equilibrium investigations suggest that Freundlich model was perfectly fit for adsorption of AO onto TTWM500. Maximum adsorption capacity $\left(q_{\max }\right)$ of $69.44 \mathrm{mg} / \mathrm{g}$ was obtained using the Langmuir equation. Adsorption kinetics could be best described by the pseudo-second-order (PSO) model. The multi-cycle sorption-desorption study showed that TTWM500 could be regenerated with the adsorption efficiency being preserved up to $87 \%$ after six cycles.
\end{abstract}

Keywords Acridine orange $\cdot$ Eco-friendly adsorbent $\cdot$ Wastewater $\cdot$ Watermelon rinds $\cdot$ Box-Behnken design

\section{Introduction}

Clean-water scarcity is becoming a global concern, especially with the fast expansion of the Earth's inhabitants and the constant climate deterioration. This expansion and the escalating anthropogenic activities such as frequent deforestation and improvised industrialization represent the main reasons behind the worldwide water crisis.

Dyes are one of the significant water contaminants. The ever-increasing use of colorants in food and beverages' industries, cosmetics, textiles, plastics, paper, and pharmaceuticals has reached worrying levels (Mekonnen and Hoekstra 2016; Liu et al. 2017; Gleick and Iceland 2018). Even traces of dyes (as low as $1 \mathrm{ppm}$ ) can highly affect a substantial volume of

Responsible Editor: Tito Roberto Cadaval Jr

Marwa El-Azazy

marwasaid@qu.edu.qa

1 Department of Chemistry and Earth Sciences, College of Arts and Sciences, Qatar University, Doha 2713, Qatar water, an issue that consequently increases the magnitude of the problem by affecting the aquatic creatures and human health. Statistics show that approximately $10^{6}$ tons of dyes are consumed worldwide per year and the quantity of dyes discharged into water sources represents $2 \%$ of this amount (Forgacs et al. 2004; Kant 2012; Ghaly et al. 2014; Basu et al. 2014; Jawad et al. 2019; El-Azazy et al. 2020; Hassan et al. 2020; El-Azazy et al. 2019a, 2019b; Prasad and Santhi 2012).

Acridine orange (AO) (IUPAC name: 3-N,3-N,6-N,6-Ntetramethylacridine-3,6-diamine, $\mathrm{C}_{17} \mathrm{H}_{20} \mathrm{CIN}_{3}$ ) is a xenobiotic, nucleic acid-selective, and cell-permeable fluorescent cationic dye. AO is broadly used for biological staining applications, lithography, block-printing, and coloring leather products (Scheme 1). According to the "safety data sheet" of AO, this dye's remarkable hazards include lethality, photodynamicity, and mutagenicity (Iessi et al. 2017; IARC 1978).

In general, wastewater treatment technologies can be categorized into chemical, physical, biological, and combinatorial (two or more of these approaches). Each of these techniques has its pros and cons. For example, chemical and physical approaches and unless being coupled to response surface methodology (RSM) would be time and resources consuming. 


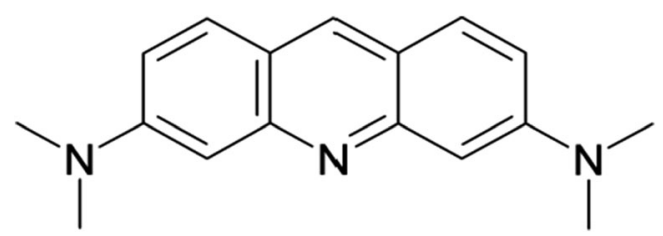

Scheme 1 Structure of acridine orange (AO)

Moreover, these schemes generally suffer from drawbacks such as low \% removal, high cost, sludge-formation, and complicated setup (Camargo et al. 2016; Verma et al. 2012; Montes-Atenas and Valenzuela 2017; Hai et al. 2007; Geaniyu et al. 2015; El-Gendy et al. 2020; Al-Saad et al. 2019; El-Azazy et al. 2019c, d). Adsorption is a promising technique that offers many advantages such as being convenient with simple setup, low cost, high removal efficiency, and good output quality.

Low-cost adsorbents represent an emerging class of adsorbents. As their name implies, these adsorbents are cost-effective, eco-friendly, and readily available. Moreover, using these wastes has a dual environmental benefit, for both waste management and wastewater treatment. Several investigations on the valorization of agro-wastes for the removal of water contaminants can be found in the literature (Basu et al. 2014; Jawad et al. 2019; El-Azazy et al. 2020; Hassan et al. 2020; ElAzazy et al. 2019a, 2019b, 2019c, 2019d; Prasad and Santhi 2012; El-Gendy et al. 2020; Al-Saad et al. 2019).

Watermelon (Citrullus lanatus) is a well-known summerfruit in which the rind covers approximately one-third of the total fruit mass. China alone produces around $2.3 \times 10^{7}$ tons of rinds per year (Chen et al. 2017). The rind biomass is considered waste and has no commercial value. As a lignocellulosic material, watermelon rinds (WMR) are rich in macromolecular polymers (e.g., cellulose, pectin, carotenoids), which in turn possess a variety of functional moieties and would facilitate the adsorption of pollutants from wastewater (Chen et al. 2017; Lakshmipathy and Sarada 2013; Lakshmipathy and Sarada 2015; Alexander et al. 2015; Husein et al. 2017; Masoudian et al. 2019; Gupta and Gogate 2016; Memon et al. 2008; Li et al. 2019; Benkaddour et al. 2018). Several studies have explored the adsorption efficiency of WM (specially rinds and seeds both raw and activated) for various contaminants. Samples of these applications are summarized in Table S1 (Masoudian et al. 2019; Gupta and Gogate 2016; Memon et al. 2008; Li et al. 2019; Benkaddour et al. 2018).

Literature survey shows that the adsorption efficiency of is affected by different factors such as $\mathrm{pH}$, adsorbent dosage (AD), dye concentration (DC), and the contact time between the adsorbent and the contaminant (ST). Yet, the majority of the reported approaches (Table S1) are one-factor-at-a-time (OFAT) based, where one variable is altered while the remainder is kept constant. This technique, and in addition to the deterioration of the method greenness, does not draw a full picture of variable-variable interactions (Elazazy 2017).
Therefore, it was imperative to develop an approach that surmounts these detriments and produces data that can be handled with a great deal of confidence. Box-Behnken (BB) design was therefore selected for the current endeavor. Two responses, \% removal of $\mathrm{AO}(\% R)$ and adsorption capacity of WMR $\left(q_{e}, \mathrm{mg} / \mathrm{g}\right)$, will be determined and maximized as a function of the four previously mentioned variables (Elazazy 2017; Elmoubarki et al. 2017; Elazazy et al. 2018; El-Azazy et al. 2021; Oladipo et al. 2015).

Prepared adsorbents will be characterized using scanning electron microscopy (SEM), sorption-desorption of $\mathrm{N}_{2}$ on the surface, Fourier transform-infrared (FT-IR), and Raman spectroscopies. Thermal stability will be assessed using thermogravimetric analysis (TGA). Identifying the adsorption mechanism will be accomplished by analyzing the adsorption equilibrium and kinetics.

\section{Materials and methods}

\section{Materials and reagents}

Watermelon rinds (WMR) were collected as a waste material (to be discarded) from the shopping centers, Doha-Qatar. Collected rinds were washed with distilled water to eliminate any dirt. All chemicals used were of the analytical grade. Sodium hydroxide, sulfuric acid, nitric acid, sodium carbonate, hydrochloric acid, and sodium tetraborate-10-hydrate were the products of Sigma-Aldrich (Darmstadt, Germany). Adsorbate tested was acridine orange dye (AO, Fluka Chemicals, Germany). Ultrapure water (18.2 $\mathrm{M} \Omega$ ) was used to prepare and dilute dye solutions. A stock solution of 100 $\mathrm{mg} / \mathrm{L}$ of $\mathrm{AO}$ was made in deionized water. The $\mathrm{pH}$ of dye solutions was attuned using a mixture of sodium tetraborate10-hydrate $\left(\mathrm{Na}_{2} \mathrm{~B}_{4} \mathrm{O}_{7} \cdot 10 \mathrm{H}_{2} \mathrm{O}, 50 \mathrm{mM}\right)$ and $0.1 \mathrm{M} \mathrm{NaOH}$ or $0.1 \mathrm{M} \mathrm{HCl}$. All experimental runs were carried out at room temperature.

\section{Instrumentation and software}

A Thermo Scientific centrifuge (SL8 Benchtop, Thermo Scientific, MA, USA) was operated to separate the supernatant. The amount of adsorbed AO was determined using a UV/ Vis spectrophotometer (Agilent diode-array, CA, USA) equipped with identical $10-\mathrm{mm}$ quartz cells. For $\mathrm{pH}$ measurements, a pH meter (Jenway, Staffordshire, UK) was used. Study of surface morphology and composition was performed using SEM (FEI, Quanta 200, Thermo Scientific, MA, USA). Existence of surface functionalities was performed using FTIR analysis (Bruker Alpha, MA, USA). Conversion of WMR into carbonaceous biomass was investigated using Raman spectroscopic analysis. Spectrum was acquired in the range of $50-3500 \mathrm{~cm}^{-1}$ operating a DXRTM 2 Raman microscope 
(Thermo Scientific, MA, USA), with a laser beam at $532 \mathrm{~nm}$ as excitation source and $10 \mathrm{~mW}$ power. The prepared adsorbents' thermal stability was assessed in the range of 50-800 ${ }^{\circ} \mathrm{C}$ using a thermal gravimetric analyzer (TGA, PerkinElmerTGA400). To determine the surface area and pore size, samples were degassed and $\mathrm{N}_{2}$ adsorption-desorption was monitored utilizing a Micromeritics ASAP2020 Accelerated Surface Area and Porosimetry System. The $\mathrm{N}_{2}$ adsorptiondesorption isotherms obtained at $77 \mathrm{~K}$ and using the Brunauer Emmett-Teller (BET) equation were utilized to determine surface area. Pore volume was ascertained employing the t-plots and Barrett-Joyner-Halenda (BJH) equation.

Minitab®19 software was used for composing and analyzing the Box-Behnken (BB) design. The software was procured from Minitab (Minitab Inc., State College, PA, USA).

\section{Preparation of AO solutions}

Contaminated water samples (artificially, $100 \mathrm{mg} / \mathrm{L}$ stock solutions) were made by the dissolution of the appropriate amounts of AO in deionized water. Serialized dilutions of $\mathrm{AO}$ were made in the same solvent, and the $\mathrm{pH}$ was tuned to the required value. Calibration curves of $\mathrm{AO}$ at the three-pH levels ventured in the design structure (low, central, and high, Table 1) were assembled using different concentrations of AO at $419 \mathrm{~nm}$.

\section{Preparation of the adsorbents}

For this step, WMR was chopped into smaller pieces (nearly $1 \mathrm{~cm} \times 1 \mathrm{~cm}$ ) and further washed with deionized water to eliminate dust and impurities. Cut pieces were dried out in the oven at $80{ }^{\circ} \mathrm{C}$ for six consecutive days. Dry rinds were broken up into smaller pieces, powdered, and sieved using a 1-mm mesh size sieve. Crushed rinds were apportioned into two parts: one-half for testing the raw sample's efficiency (raw, RWM) and the other half for testing as thermally treated samples at two different temperatures, $250{ }^{\circ} \mathrm{C}$ and $500{ }^{\circ} \mathrm{C}$. The crushed rinds were then placed in a covered crucible and were burnt in a furnace at the mentioned temperatures for $2 \mathrm{~h}$. Soon after, the crucibles were left to cool down before collecting the burnt samples, and the obtained portions were labeled as TTWM250 and TTWM500.

Table 1 Process factors and their boundaries

\begin{tabular}{llll}
\hline Factors & High (+) & Mid (0) & Low (-) \\
\hline pH value (pH, A, pH unit) & 11.0 & 7.5 & 4.0 \\
Adsorbent dosage (AD, B, mg/15 mL) & 125 & 75 & 25 \\
Dye concentration (DC, C, mg/L) & 25 & 15 & 5 \\
Contact time (ST, D, min) & 240 & 130 & 20 \\
\hline
\end{tabular}

\section{Assessment of adsorption competency of the prepared WMR}

The adsorption capability of the three adsorbents was evaluated by contrasting the values of the $\% R$ and $q_{e}$ using Eqs. 1 and 2 , respectively, and operating the conditions mentioned in Table 1. TTWM500 showed the best performance in terms of both responses (Table 1).

$$
\begin{aligned}
& \% R=\frac{\left(C_{o}-C_{e}\right)}{C_{o}} \times 100 \% \\
& q_{e}=\frac{\left(C_{o}-C_{e}\right)}{W} V
\end{aligned}
$$

In the above equations, $q_{e}$ stands for adsorption capacity, $C_{0}$ and $C_{e}$ stand for the primary and equilibrium concentrations of $\mathrm{AO}$ in solution $(\mathrm{mg} / \mathrm{L}), V$ is the volume of the solution $(\mathrm{L}), W$ is the mass of the adsorbent in grams. To determine the effect of experimental parameters on the adsorption process, the experimental structure shown in Table 2 was followed, and the two responses were determined using Eqs. 1 and 2. The absorbance of the supernatant for each experiment was measured against a blank prepared simultaneously omitting the AO.

\section{Response surface methodology (RSM)}

TTWM500, and following the comparison shown in Table 2, was the adsorbent of choice for the subsequent investigations. A response surface methodological approach, BB design was used to investigate the impact of the different variables on the measured responses. Two responses, $\% R$ and $q_{e}$, were optimized as a function of four factors. The target was to maximize both responses. In this itinerary, 28 experimental runs (including four central points) were conducted over three blocks. Regression equations were obtained by including blocks in the model. The design structure is shown in Table 3.

\section{Equilibrium and kinetics investigation}

To get the equilibrium features of the adsorption of $\mathrm{AO}$ onto WMR, a $1000 \mathrm{mg} / \mathrm{L}$ solution of AO was formulated. Additional dilutions of the stock solution $(5-400 \mathrm{mg} / \mathrm{L})$ were

Table 2 Performance of tested adsorbents. Assessment was carried out using a variable blend of $\mathrm{pH}=7.00 \pm 0.20, \mathrm{DC}=20 \mathrm{mg} / \mathrm{L}, \mathrm{AD}=100 \mathrm{mg}$ $15 \mathrm{~mL}$, and $\mathrm{ST}=30 \mathrm{~min}$

\begin{tabular}{lll}
\hline Adsorbent type & $\% R^{*}$ & $q_{e}(\mathrm{mg} / \mathrm{g})^{* *}$ \\
\hline RWM & 77.17 & 2.31 \\
TTWM250 & 96.21 & 2.88 \\
TTWM500 & 98.32 & 2.94 \\
\hline
\end{tabular}

${ }^{*, * *}$ Calculated using Eqs. 1 and 2, respectively 
Table 3 Experimental structure of the BB design as generated by Minitab® 19

\begin{tabular}{|c|c|c|c|c|c|c|c|c|c|c|c|}
\hline Run\# & Block & $\mathrm{pH}$ & $\mathrm{AD}$ & $\mathrm{DC}$ & $\mathrm{ST}$ & $\% R$ (obs.*) & $\% R$ (pred. $^{* *}$ ) & $\mathrm{Er}^{* * * *}$ & $q_{e}($ obs.*) & $q_{e}$ pred. $\left.^{* *}\right)$ & $\mathrm{Er}^{* * *}$ \\
\hline 01 & 2 & $11(+)$ & $75(0)$ & $15(0)$ & $240(+)$ & 88.23 & 89.05 & 0.82 & 4.41 & 4.43 & 0.02 \\
\hline 02 & 2 & $7.5(0)$ & $25(-)$ & $25(+)$ & $130(0)$ & 88.21 & 86.70 & 1.51 & 21.48 & 20.60 & 0.88 \\
\hline 03 & 2 & $4(-)$ & $75(0)$ & $15(0)$ & $20(-)$ & 94.50 & 93.33 & 1.17 & 4.71 & 4.52 & 0.19 \\
\hline 04 & 2 & $4(-)$ & $75(0)$ & $15(0)$ & $240(+)$ & 98.54 & 98.06 & 0.48 & 4.93 & 4.71 & 0.22 \\
\hline 05 & 2 & $7.5(0)$ & $25(-)$ & $5(-)$ & $130(0)$ & 93.74 & 90.77 & 2.97 & 4.66 & 4.35 & 0.31 \\
\hline 06 & 2 & $7.5(0)$ & $75(0)$ & $15(0)$ & $130(0)$ & 94.93 & 95.06 & 0.13 & 4.66 & 4.66 & 0.00 \\
\hline 07 & 2 & $11(+)$ & $75(0)$ & $15(0)$ & $20(-)$ & 86.56 & 86.65 & 0.09 & 4.23 & 4.27 & 0.04 \\
\hline 08 & 2 & $7.5(0)$ & $125(+)$ & $5(-)$ & $130(0)$ & 93.78 & 94.33 & 0.55 & 0.94 & 0.94 & 0.00 \\
\hline 09 & 2 & $7.5(0)$ & $125(+)$ & $25(+)$ & $130(0)$ & 97.71 & 98.13 & 0.42 & 4.88 & 5.03 & 0.15 \\
\hline 10 & 1 & $7.5(0)$ & $75(0)$ & $5(-)$ & $20(-)$ & 93.74 & 93.36 & 0.38 & 1.56 & 1.52 & 0.04 \\
\hline 11 & 1 & $7.5(0)$ & $75(0)$ & $15(0)$ & $130(0)$ & 95.84 & 95.06 & 0.78 & 4.73 & 4.66 & 0.07 \\
\hline 12 & 1 & $11(+)$ & $125(+)$ & $15(0)$ & $130(0)$ & 87.72 & 81.54 & 6.18 & 2.63 & 2.50 & 0.13 \\
\hline 13 & 1 & $7.5(0)$ & $75(0)$ & $25(+)$ & $240(+)$ & 97.08 & 97.09 & 0.01 & 8.04 & 7.97 & 0.07 \\
\hline 14 & 1 & $4(-)$ & $125(+)$ & $15(0)$ & $130(0)$ & 98.46 & 99.40 & 0.94 & 2.94 & 3.09 & 0.15 \\
\hline 15 & 1 & $7.5(0)$ & $75(0)$ & $15(0)$ & $130(0)$ & 94.54 & 95.06 & 0.52 & 4.61 & 4.66 & 0.05 \\
\hline 16 & 1 & $7.5(0)$ & $75(0)$ & $25(+)$ & $20(-)$ & 95.63 & 95.95 & 0.32 & 7.86 & 7.76 & 0.10 \\
\hline 17 & 1 & $7.5(0)$ & $75(0)$ & $5(-)$ & $240(+)$ & 99.13 & 98.56 & 0.57 & 1.63 & 1.60 & 0.03 \\
\hline 18 & 1 & $4(-)$ & $25(-)$ & $15(0)$ & $130(0)$ & 75.33 & 81.88 & 6.55 & 11.30 & 11.53 & 0.23 \\
\hline 19 & 1 & $11(+)$ & $25(-)$ & $15(0)$ & $130(0)$ & 91.89 & 83.74 & 8.15 & 13.78 & 12.69 & 1.09 \\
\hline 20 & 3 & $4(-)$ & $75(0)$ & $25(+)$ & $130(0)$ & 90.86 & 90.45 & 0.41 & 7.39 & 7.32 & 0.07 \\
\hline 21 & 3 & $7.5(0)$ & $25(-)$ & $15(0)$ & $20(-)$ & 76.14 & 88.34 & 12.2 & 11.20 & 12.21 & 1.01 \\
\hline 22 & 3 & $7.5(0)$ & $75(0)$ & $15(0)$ & $130(0)$ & 94.78 & 95.06 & 0.28 & 4.70 & 4.66 & 0.04 \\
\hline 23 & 3 & $7.5(0)$ & $125(+)$ & $15(0)$ & $240(+)$ & 99.96 & 98.95 & 1.01 & 2.97 & 2.92 & 0.05 \\
\hline 24 & 3 & $4(-)$ & $75(0)$ & $5(-)$ & $130(0)$ & 97.76 & 98.01 & 0.25 & 1.61 & 1.65 & 0.04 \\
\hline 25 & 3 & $7.5(0)$ & $125(+)$ & $15(0)$ & $20(-)$ & 98.71 & 95.95 & 2.76 & 2.93 & 2.87 & 0.06 \\
\hline 26 & 3 & $11(+)$ & $75(0)$ & $25(+)$ & $130(0)$ & 90.88 & 91.45 & 0.57 & 7.51 & 7.83 & 0.32 \\
\hline 27 & 3 & $7.5(0)$ & $25(-)$ & $15(0)$ & $240(+)$ & 81.66 & 92.39 & 10.73 & 11.85 & 12.93 & 1.08 \\
\hline 28 & 3 & $11(+)$ & $75(0)$ & $5(-)$ & $130(0)$ & 76.30 & 79.99 & 3.69 & 1.27 & 1.37 & 0.10 \\
\hline
\end{tabular}

${ }^{*}$ Obs., experimental values; ${ }^{* *}$ Pred., predicted values following the process of response transformation. ${ }^{* * *} E r$, absolute error $=\mid(\mathrm{Obs}-$ Pred. $) \mid$

prepared using the same solvent and the $\mathrm{pH}$ was attuned to a value of $7.00 \pm 0.20$ using the mentioned borate- $\mathrm{HCl}$ or borate- $\mathrm{NaOH}$ solutions. Quantities of TTWM500 $(0.100 \pm$ $0.005 \mathrm{~g}$ ) were inserted into $13 \mathrm{~mL}$ of the formerly made solutions, and then the solution was stirred at a speed of $150 \mathrm{rpm}$ for $2 \mathrm{~h}$ and then filtered. Investigation of the adsorption kinetics was carried out using $200 \mathrm{~mL}$ of AO solution $(100 \mathrm{mg} / \mathrm{L}$, $\mathrm{pH} 4.00 \pm 0.20$ ) and $\sim 1 \mathrm{~g}$ of TTWM500 with shaking. One sample was taken at a time range of around $1 \mathrm{~min}$ and over a total time span of $30 \mathrm{~min}$. Investigations of equilibrium and kinetics were conducted at room temperature.

\section{Desorption and reusability studies}

To explore the potential of adsorbent reusability, TTWM500 (2.5 g) was first equilibrated with $1 \mathrm{~L}$ of $15 \mathrm{mg} / \mathrm{L}$ dye solution over a period of $4 \mathrm{~h}$ at room temperature. The mixture was then filtered. The adsorbent was washed with distilled water to remove any non-adsorbed traces of the $\mathrm{AO}$, and then dried in the oven at $80{ }^{\circ} \mathrm{C}$ overnight. The eluents used in the current study were $0.1 \mathrm{M}$ of $\mathrm{HCl}, \mathrm{H}_{2} \mathrm{SO}_{4}, \mathrm{HNO}_{3}, \mathrm{Na}_{2} \mathrm{CO}_{3}, \mathrm{NaOH}$, and $\mathrm{H}_{2} \mathrm{O}$. The desorption experiment was performed by mixing $100 \mathrm{mg}$ of the AO-loaded adsorbent with $10 \mathrm{~mL}$ of the eluent and stirring at $150 \mathrm{rpm}$ for $1 \mathrm{~h}$. The mixture was filtered, and the absorbance of the filtrate was measured using the UV-Vis spectrophotometer. Each of the desorption experiments was repeated three times and the average values of desorbed amount were plotted. Error bars were used to express the standard deviation between the replicate measurements.

Recovery studies were carried using $0.1 \mathrm{M} \mathrm{NaOH}$ solution. Prior to that, an amount of $200 \mathrm{mg}$ of TTWM500 was equilibrated with $40 \mathrm{~mL}$ of $15 \mathrm{mg} / \mathrm{L}$ AO solution $(\mathrm{pH} 4.0 \pm 0.2)$ for $4 \mathrm{~h}$ at room temperature. The obtained mixture was then filtered, and the absorbance of the filtrate was measured at 491 $\mathrm{nm}$. The loaded adsorbent was washed with distilled water and 
then left in contact with $20 \mathrm{~mL}$ of $0.1 \mathrm{M} \mathrm{NaOH}$ for $1 \mathrm{~h}$. The adsorbent was washed and dried in the next step at $80^{\circ} \mathrm{C}$ for $2 \mathrm{~h}$ and this adsorbent was used again for a second adsorption cycle. This process was renewed six times, and in each cycle, the removal efficiency $(\% R)$ was determined.

\section{Results and discussion}

\section{Box-Behnken (BB) design}

The main endeavor we are taking herein is to maximize the adsorption efficiency and the removal capability of WMR. Concomitantly, conservation of method greenness via recycling of the WMR as an agro-waste into a waste removing model adsorbent using a green approach was the task undertaken. These targets were tackled using BB design as an approach. As a response surface design, BB design can proficiently determine the first- and second-order constants and consequently provide an idea about the experimental response surface's shape. BB design is a straightforward design with no involvement of a precursor factorial design. As a multivariate approach, this design is a cost-effective option as it comprises fewer design points and hereafter a small number of experimental runs contrasted to other RSM designs (Elazazy 2017). The experimental structure is displayed in Table 3.

\section{Data analysis and development of regression models}

Quality charts were utilized to confirm variable significance. Pareto chart of the standardized effects was employed as a tool to determine the statistically significant factors. Figure $1-\mathrm{left}$ panel-shows that while $\% R$ was most affected by $\mathrm{pH}(\mathrm{A})$ followed by the AD (B), the DC (C) was not statistically substantial. However, the right panel shows that DC (C) in the case of $q_{e}$ was the most statistically weighty factor.

Figure 2 demonstrates the residual plots (four types of charts in each panel: normal probability plots, versus fits, histogram of residuals, and versus order). Residual plots were used to confirm that the original assumption of ordinary least square was fulfilled, and so is the goodness-of-fit in regression. Plots shown for both responses confirm that data are coming from a normal population where residuals look normally distributed at constant variance with almost no outliers and no correlation between residuals.

The outcome of using BB design is the regression models shown below (Eqs. 3 and 4). These two models were obtained following Box-Cox transformation with a forward selection of terms in the case of $\% R$ (Box and Cox 1964; Antony 2003; Bruns et al. 2006). Moreover, these equations could be used to get the magnitude and direction of tested variables by comparing their sign and the coefficient, respectively. The overall effect of a variable could be gauged considering the contributions from linear, quadratic, and two-way interactions.

$$
\begin{gathered}
\left(\% R^{\lambda}-1\right) /\left(\lambda \times g^{(\lambda-1)}\right)=-2.69+4.789 \mathrm{pH}+0.3548 \mathrm{AD} \\
-1.085 \mathrm{DC}+0.0191 \mathrm{ST}-0.3708 \mathrm{pH}^{2} \\
-0.000955 \mathrm{AD}^{2}+0.000121 \mathrm{ST}^{2} \\
-0.02604 \mathrm{pH} \times \mathrm{AD}+0.1265 \mathrm{pH} \\
\times \mathrm{DC}-0.00230 \mathrm{pH} \times \mathrm{ST}+0.00403 \mathrm{AD} \\
\times \mathrm{DC}-0.001082 \mathrm{DC} \times \mathrm{ST}, \\
(\lambda=5, g=92.0315 \text { is the geometric mean of } \%) \\
{\left[R^{2}=97.10 \%, R^{2}(\mathrm{adj})=94.78 \%, R^{2}(\mathrm{pred})=88.40 \%\right]} \\
\ln \left(\mathrm{q}_{\mathrm{e}}\right)=1.223+0.0454 \mathrm{pH}-0.02750 \mathrm{AD}+0.1487 \mathrm{DC} \\
+0.000423 \mathrm{ST}-0.00317 \mathrm{pH}+0.000103 \mathrm{AD}{ }^{2} \\
-0.002844 \mathrm{DC}-0.000000 \mathrm{ST}-0.000443 \mathrm{pH} \\
\times \mathrm{AD}+0.001818 \mathrm{pH} \times \mathrm{DC}-0.000002 \mathrm{pH} \\
\times \mathrm{ST}+0.000060 \mathrm{AD} \times \mathrm{DC}-0.000002 \mathrm{AD} \\
\times \mathrm{ST}-0.000005 \mathrm{DC} \times \mathrm{ST}, \\
{\left[\mathrm{R}^{2}=99.76 \%, \mathrm{R}^{2}(\mathrm{adj})=99.40 \%, \mathrm{R}^{2}(\mathrm{pred})=98.03 \%\right]}
\end{gathered}
$$

As shown in Table 3, the measured responses (observed) as well as the responses anticipated by the regression model (predicted) are compared and the comparison is given in terms of the absolute error (Er). Results show good agreement between both (Table 3). Moreover, the regression model prediction capability was confirmed by the high values of $R^{2}$ (pred).

\section{Analysis of variance (ANOVA)}

Parallel to the use of quality charts, analysis of variance (ANOVA) was employed to corroborate the variable significance at $95 \%$ CI. Results of the ANOVA for both responses are summarized in Table 4. Variable significance is verified when $P$-values are $<0.05$. For example, linear and squared variables: $\mathrm{pH}, \mathrm{AD}$, and $\mathrm{ST}$ as well as the two-way interaction effects of $\mathrm{pH} \times \mathrm{DC}, \mathrm{pH} \times \mathrm{AD}$, and $\mathrm{DC} \times \mathrm{AD}$ were statistically significant for the $\% R$ with $P$-values being $<0.05$. Lack-of-fit values for both responses were statistically insignificant implying the goodness-of-fit of the proposed models (Elazazy 2017; Box and Cox 1964; Antony 2003; Bruns et al. 2006).

\section{Contour (2D), surface (3D), and optimization plots}

Contour plots disclose a three-dimensional surface on a twodimensional plane, where the two predictors $X$ and $Y$ are shown on the $y$-axis while a response variable $Z$ is displayed 

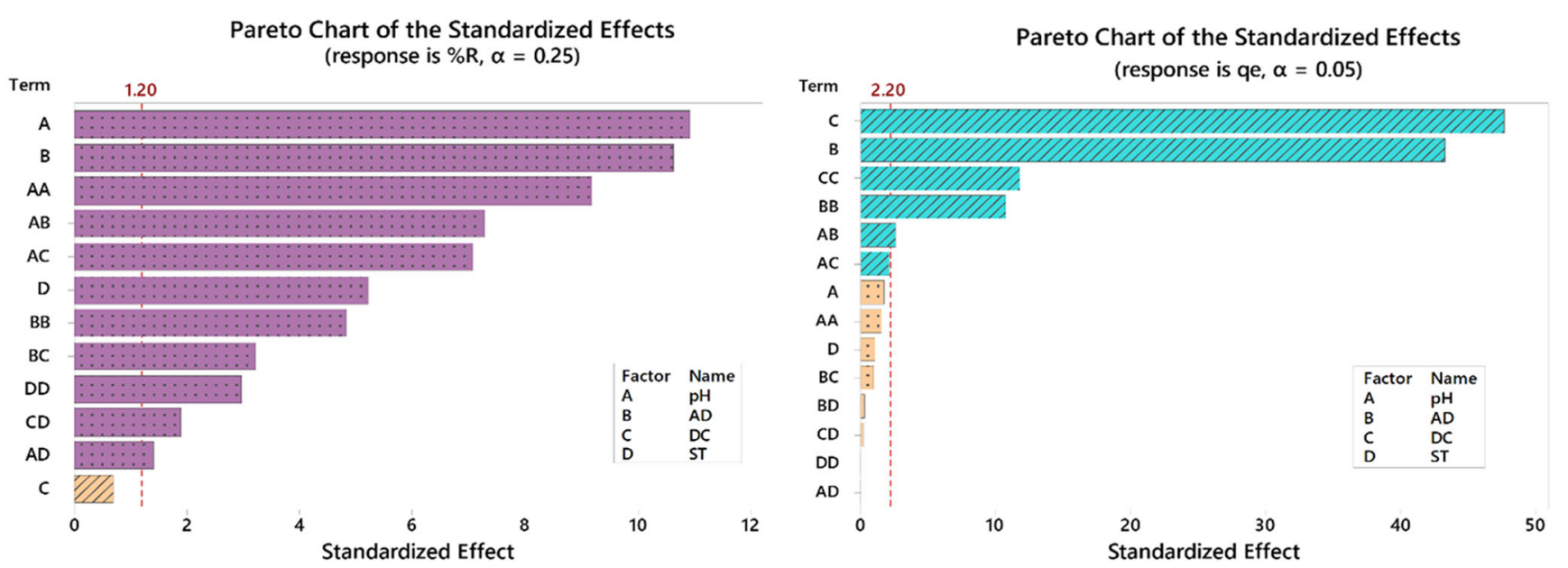

Fig. 1 Pareto chart of standardized effects for both responses ( $\% R-$ left panel and $q_{e}$ - right panel)

as contours. In Fig. 3 - upper panel - the densest green region denotes an area with the ultimate response. The $2 \mathrm{D}$ plot of $\% R$ for example displays $100 \%$ removal of $\mathrm{AO}$ at a $\mathrm{pH}$ range of 5-7.5 and an $\mathrm{AD}$ of $80-120 \mathrm{mg} / 50 \mathrm{~mL}$. On the other hand, surface plots are graphs of three-dimensional data that illustrate a functional relationship between a designated dependent variable $(Z)$, and two independent variables $(X$ and $Y$ ), rather than showing the individual data points. Figure $3-$ lower panel - exhibits the 3D arrangement. Same conclusions as in the case of the contour plots can be derived in the case of $\mathrm{pH}-\mathrm{AD} 3 \mathrm{D}-\mathrm{plot}$, where the maximum curvature denotes the maximum $\% R$.

Optimization plots - figures are not shown - display the best level for each factor as well as the best factorial blend to maximize each response. The favorability of the blend is denoted by the value of the individual desirability function $(d)$. Overall, as the value of $d$ gets close to 1.000 , the factorial blend is then more favorable (Elazazy 2017; Box and Cox 1964; Antony 2003; Bruns et al. 2006). Optimum conditions that maximize the $\% R$ were $\mathrm{pH}=4.0, \mathrm{AD}=125 \mathrm{mg} / 50 \mathrm{~mL}$, $\mathrm{DC}=5 \mathrm{mg} / \mathrm{L}$, and ST $=240 \mathrm{~min}$. This blend could achieve a removal of $100 \%$ and a $d=1.000$. In the case of $q_{e}$, however, a blend of $\mathrm{pH}=11, \mathrm{AD}=25 \mathrm{mg} / 50 \mathrm{~mL}, \mathrm{DC}=25 \mathrm{mg} / \mathrm{L}$, and $\mathrm{ST}$ $=240 \mathrm{~min}$ could achieve an adsorption capacity of $22.64 \mathrm{mg} / \mathrm{g}$ with a $d=1.000$.

\section{Adsorbent characterization}

\section{SEM and BET analyses}

The structural features of the surface of the three adsorbents were studied using SEM and BET analyses. Figures $4 a, 4 b$, and $4 \mathrm{c}$ show the SEM images of RWM, TTWM250, and TTWM500 at $\times 1000$ magnification, respectively. The SEM micrograph of RWM (Fig. 4a) shows no formation of pores with a homogenous, smooth surface, in contrast to TTWM250 and TTWM500; Figs. $4 \mathrm{~b}$ and $4 \mathrm{c}$ show clear formation of pores. This could be ascribed to the thermal activation process and the conversion of the biomass into a carbonaceous material with an advanced pore structure. Other images for TTWM500 at magnification $\times 250$ and $\times 1000$ are shown in Fig. 4 - lower panel. Moreover, the SEM images show that TTWM500 has a more advanced intra-pore structure compared to TTWM250 (Li et al. 2019).

BET analysis results of the three adsorbents are reported in Table 5. Obtained results show that the surface areas of the raw and biochar adsorbents are not that high compared to the previously reported surface areas of other waste-derived carbonaceous materials (Al-Saad et al. 2019; El-Azazy et al. 2019c, 2019d). However, in comparison to the untreated WM-derived adsorbents (Table S1), the obtained surface area is reasonable (Li et al. 2019). TTWM500 showed the highest surface area, pore-volume, and pore radius among the tested adsorbents. The $\mathrm{N}_{2}$ adsorption-desorption isotherms for the three adsorbents are shown in Fig. 5. As per the IUPAC classifications for the porous materials at $1 \mathrm{~atm}$ and $77 \mathrm{~K}$, the RWM surface is mainly microporous with few mesopores. At the same time, TTWM250 and TTWM500 are mostly mesoporous with fewer macropores (Rouqueroltd et al. 1994). The three adsorbents show type III adsorption isotherms with a significant hysteresis H3 - type loop, indicating that multilayer adsorption is taking place on plate-like pores.

\section{FT-IR and Raman spectroscopic analyses}

Figure 6a shows the FT-IR spectra of the as-prepared adsorbents, while Fig. $6 \mathrm{~b}$ shows a comparison between the spectra of TTWM500 before and after adsorption of AO as well as the spectrum of the free AO. As shown in Fig. 6a - upper panel (RWM) - a broad peak can be observed at $3300 \mathrm{~cm}^{-1}$ and could be assigned to the $-\mathrm{OH}$ group that might be coming from physical and crystalline water. This peak is also observed in TTWM250 with lower intensity probably due to thermal treatment, and it has almost completely disappeared in 


\section{Residual Plots for \%R}
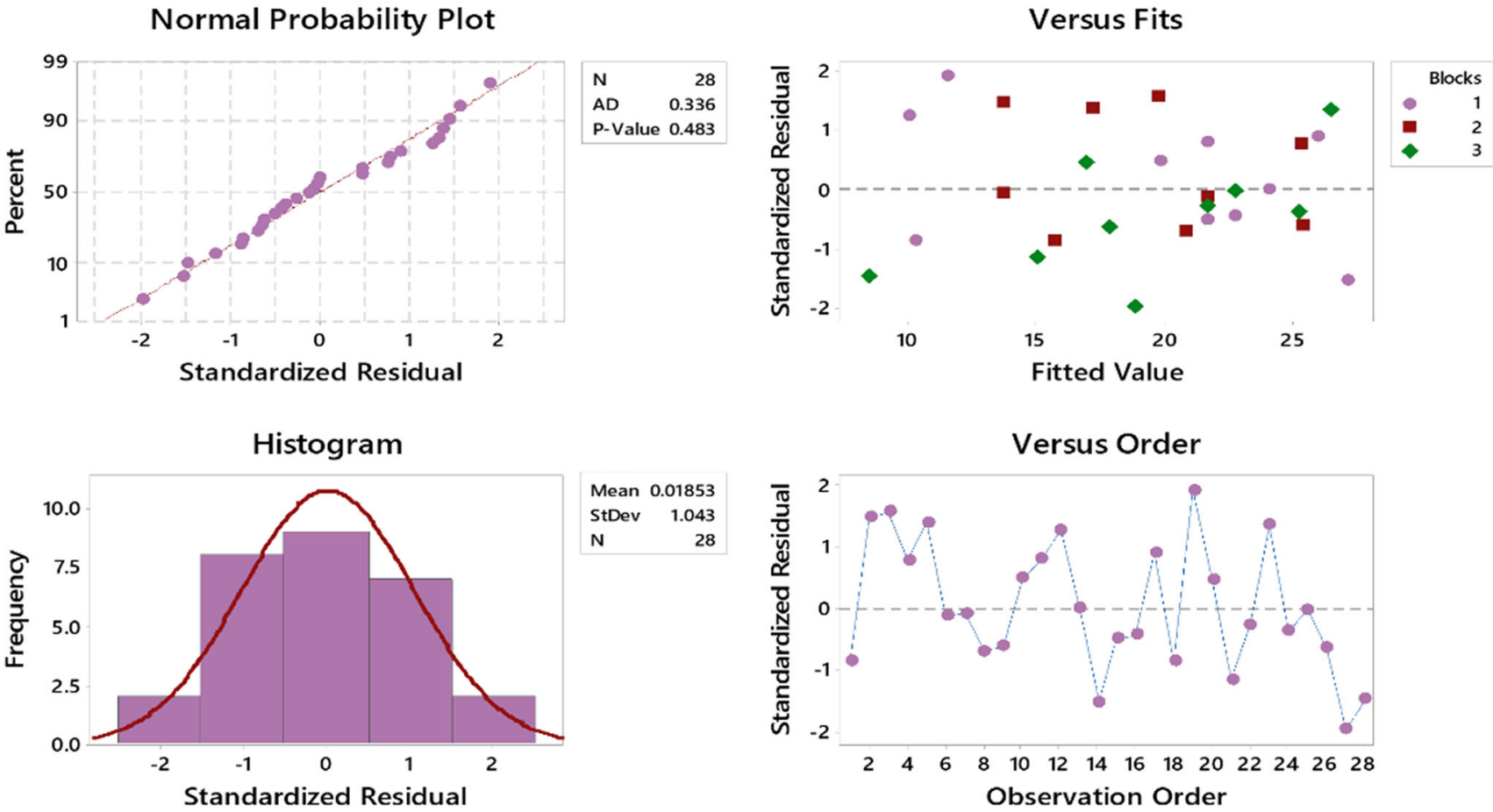

\section{Residual Plots for qe}
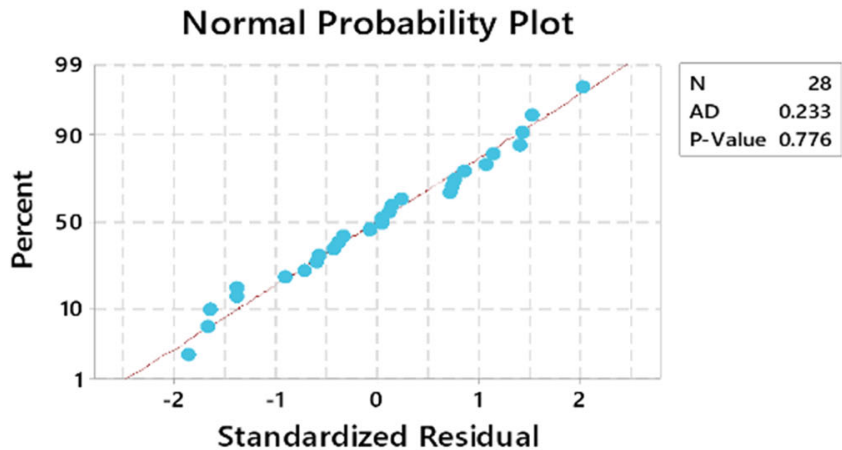

Histogram
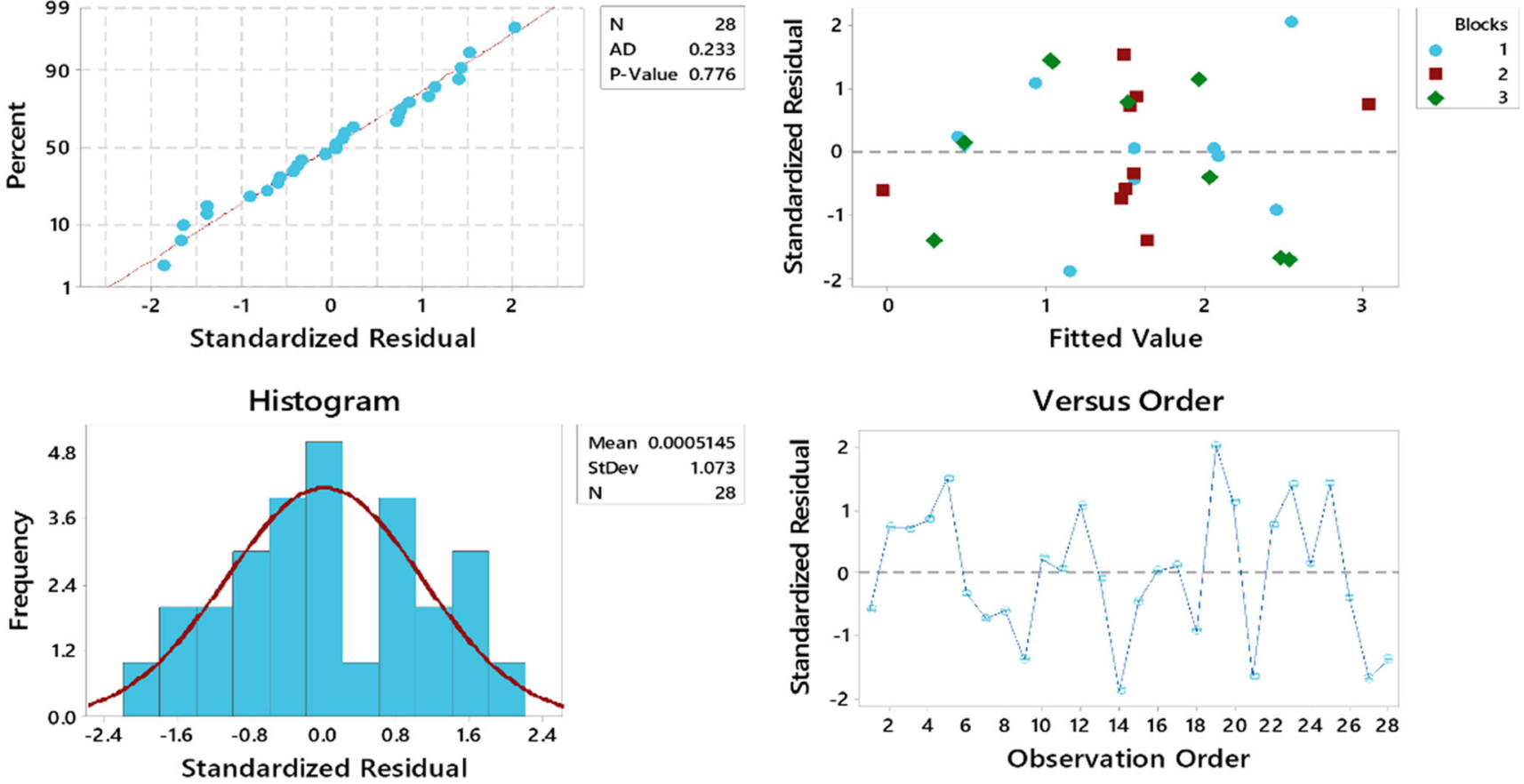

Fig. 2 Residual plots of both responses (\%R - upper panel and $q_{e}$ - lower panel)

TTWM500. A small peak can be observed at $2916 \mathrm{~cm}^{-1}$ in $\mathrm{RWM}$, corresponding to the $\mathrm{C}-\mathrm{H}$ symmetric and asymmetric stretching vibrations. The same peak could be observed in
TTWM250 with lower intensity and it completely disappeared in TTWM500. The peak (in all three adsorbents) at around $1600 \mathrm{~cm}^{-1}$ could be assigned to $\mathrm{C}=\mathrm{C}$ stretching. 
Table 4 Results of the ANOVA for the assessed responses

\begin{tabular}{|c|c|c|c|c|c|c|c|c|c|c|}
\hline \multirow{2}{*}{$\begin{array}{l}\text { Response } \\
\text { Source }\end{array}$} & \multirow[b]{2}{*}{$\mathrm{DF}^{*}$} & \multicolumn{4}{|l|}{$q_{e}$} & \multicolumn{5}{|l|}{$\% R$} \\
\hline & & Adj SS* & Adj MS* & $F$-value* & $P$-value* & $\mathrm{DF}^{*}$ & Adj SS* & Adj MS* & $F$-value* & $P$-value* \\
\hline Model & 16 & 15.5658 & 0.97286 & 281.46 & 0.000 & 12 & 787.334 & 65.611 & 41.88 & 0.000 \\
\hline Blocks & 2 & 0.0114 & 0.00568 & 1.64 & 0.238 & & & & & \\
\hline Linear & 4 & 14.3229 & 3.58073 & 1035.96 & 0.000 & 4 & 407.172 & 101.793 & 64.98 & 0.000 \\
\hline $\mathrm{pH}$ & 1 & 0.0105 & 0.01047 & 3.03 & 0.110 & 1 & 186.911 & 186.911 & 119.32 & 0.000 \\
\hline $\mathrm{AD}$ & 1 & 6.4724 & 6.47244 & 1872.58 & 0.000 & 1 & 176.911 & 176.911 & 112.94 & 0.000 \\
\hline $\mathrm{DC}$ & 1 & 7.8358 & 7.83578 & 2267.02 & 0.000 & 1 & 0.784 & 0.784 & 0.50 & 0.490 \\
\hline ST & 1 & 0.0042 & 0.00423 & 1.22 & 0.292 & 1 & 42.566 & 42.566 & 27.17 & 0.000 \\
\hline Square & 4 & 1.1863 & 0.29658 & 85.80 & 0.000 & 3 & 193.680 & 64.560 & 41.21 & 0.000 \\
\hline $\mathrm{pH}^{2}$ & 1 & 0.0090 & 0.00900 & 2.60 & 0.135 & 1 & 132.060 & 132.060 & 84.30 & 0.000 \\
\hline $\mathrm{AD}^{2}$ & 1 & 0.3966 & 0.39655 & 114.73 & 0.000 & 1 & 36.458 & 36.458 & 23.27 & 0.000 \\
\hline $\mathrm{DC}^{2}$ & 1 & 0.4821 & 0.48214 & 139.49 & 0.000 & & & & & \\
\hline $\mathrm{ST}^{2}$ & 1 & 0.0000 & 0.00001 & 0.00 & 0.970 & 1 & 13.729 & 13.729 & 8.76 & 0.010 \\
\hline 2-way interactions & 6 & 0.0444 & 0.00740 & 2.14 & 0.130 & 5 & 186.482 & 37.296 & 23.81 & 0.000 \\
\hline $\mathrm{pH} \times \mathrm{AD}$ & 1 & 0.0241 & 0.02406 & 6.96 & 0.023 & 1 & 83.053 & 83.053 & 53.02 & 0.000 \\
\hline $\mathrm{pH} \times \mathrm{DC}$ & 1 & 0.0162 & 0.01620 & 4.69 & 0.053 & 1 & 78.385 & 78.385 & 50.04 & 0.000 \\
\hline $\mathrm{pH} \times \mathrm{ST}$ & 1 & 0.0000 & 0.00000 & 0.00 & 0.979 & 1 & 3.138 & 3.138 & 2.00 & 0.177 \\
\hline $\mathrm{AD} \times \mathrm{DC}$ & 1 & 0.0036 & 0.00361 & 1.04 & 0.329 & 1 & 16.243 & 16.243 & 10.37 & 0.006 \\
\hline $\mathrm{AD} \times \mathrm{ST}$ & 1 & 0.0004 & 0.00041 & 0.12 & 0.737 & & & & & \\
\hline $\mathrm{DC} \times \mathrm{ST}$ & 1 & 0.0001 & 0.00013 & 0.04 & 0.847 & 1 & 5.662 & 5.662 & 3.61 & 0.077 \\
\hline Error & 11 & 0.0380 & 0.00346 & & & 15 & 23.497 & 1.566 & & \\
\hline Lack-of-fit & 10 & 0.0377 & 0.00377 & 12.53 & 0.217 & 14 & 22.394 & 1.600 & 1.45 & 0.580 \\
\hline Pure error & 1 & 0.0003 & 0.00030 & & & 1 & 1.103 & 1.103 & & \\
\hline Total & 27 & 15.6038 & & & & 27 & 810.831 & & & \\
\hline
\end{tabular}

$* D F$, degrees of freedom; Adj SS, adjusted sums of squares; and Adj $M S$, adjusted mean of squares

Moreover, the spectra show two peaks at $1379 \mathrm{~cm}^{-1}$, which corresponds to methyl group vibration, and $1060 \mathrm{~cm}^{-1}$, which could be ascribed to $\mathrm{C}=\mathrm{O}$ vibration of carboxylic acid, aldehyde, and ketone (Abbas and Ahmed 2016; Reddy et al. 2014; López-velandia et al. 2014; Jawad et al. 2018; Chaudhari and Singhal 2015). The obtained data confirm the existence of different functional moieties on the surface of RWM with a lower intensity in the case of TTWM300 and the same groups almost disappear in TTWM500 due to the thermal treatment, an issue that has a significant effect on the adsorption efficiency towards AO dye.

On the other hand, Fig. $6 \mathrm{~b}$ shows the spectrum of TTWM500 after adsorption of AO. As shown, the spectrum indicates some changes compared to the spectra of free AO, and TTWM500 before adsorption. These changes include alterations in intensities, shifts in position, and even complete disappearance of the band. For example, spectrum of free AO (Fig. 6b) shows a band at $2928 \mathrm{~cm}^{-1}$ which could be ascribed to the $\mathrm{C}-\mathrm{H}$ stretching vibration and a broad peak in the range of $2750-3450 \mathrm{~cm}^{-1}$ which could be assigned to $-\mathrm{NH}^{+}$of AO. These two bands almost disappear in the spectrum after adsorption. Similarly, the spectrum of free AO shows a band in the range of $1573-1590 \mathrm{~cm}^{-1}$ which could be attributed to the skeletal vibration of the phenyl ring of AO. These bands shift to $1562 \mathrm{~cm}^{-1}$ in the spectrum of TTWM500 after adsorption (this peak was not in the spectrum of TTWM500 before adsorption). The sharp peak at $1497 \mathrm{~cm}^{-1}$ which can be assigned to the aliphatic $\mathrm{CN}$ stretching coupled to the aromatic $\mathrm{C}=\mathrm{C}$ (in ring) vibrations is absent in the spectrum after adsorption. Instead, a small peak at $1501 \mathrm{~cm}^{-1}$ appears, which could be a confirmation for the existence of $\mathrm{AOH}^{+}$on the surface of the adsorbent. A similar observation could be reported for the peak at $1633 \mathrm{~cm}^{-1}$ in the spectrum of AO which could be ascribed to the $\mathrm{C}-\mathrm{C}$ stretching band and the scissoring band of N-H. Upon adsorption, the later peak disappears. The sharp peak at $1166 \mathrm{~cm}^{-1}$ in the spectrum of free $\mathrm{AO}$ which could be due to the in-plane $\mathrm{C}-\mathrm{H}$ and $\mathrm{N}-\mathrm{H}$ bending shifts to $1160 \mathrm{~cm}^{-1}$ with much less intensity and sharpness. The peak at $919 \mathrm{~cm}^{-1}$ which might be due to the rocking of N-H shifts to $883 \mathrm{~cm}^{-1}$ following adsorption. The medium peak at $696 \mathrm{~cm}^{-1}$ which could be due to $\mathrm{N}-\mathrm{H}$ twisting disappears upon adsorption.

These findings and the observed shift in the N-H vibrational frequencies following the adsorption and compared to the free $\mathrm{AO}$ suggest the occurrence of an interaction between the 


\section{Contour Plots of \%R}
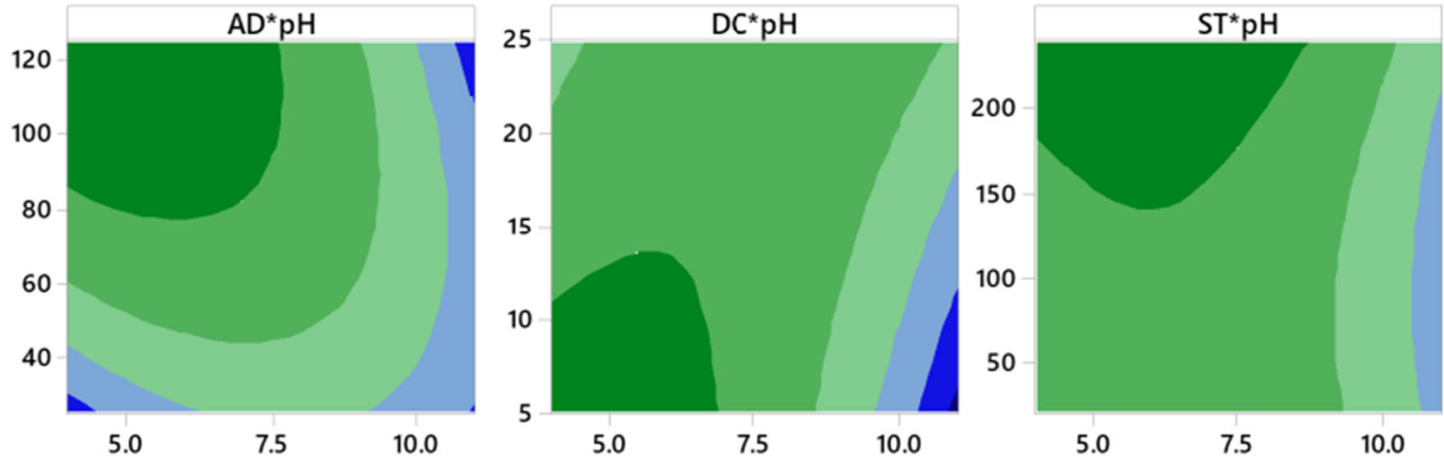

\begin{tabular}{|c|}
\hline$\% R$ \\
$<80$ \\
$80-84$ \\
$84-88$ \\
$88-92$ \\
$92-96$ \\
$96-100$ \\
$>100$ \\
\hline Hold Values \\
pH 7.5 \\
AD 75 \\
DC 15 \\
ST 130
\end{tabular}
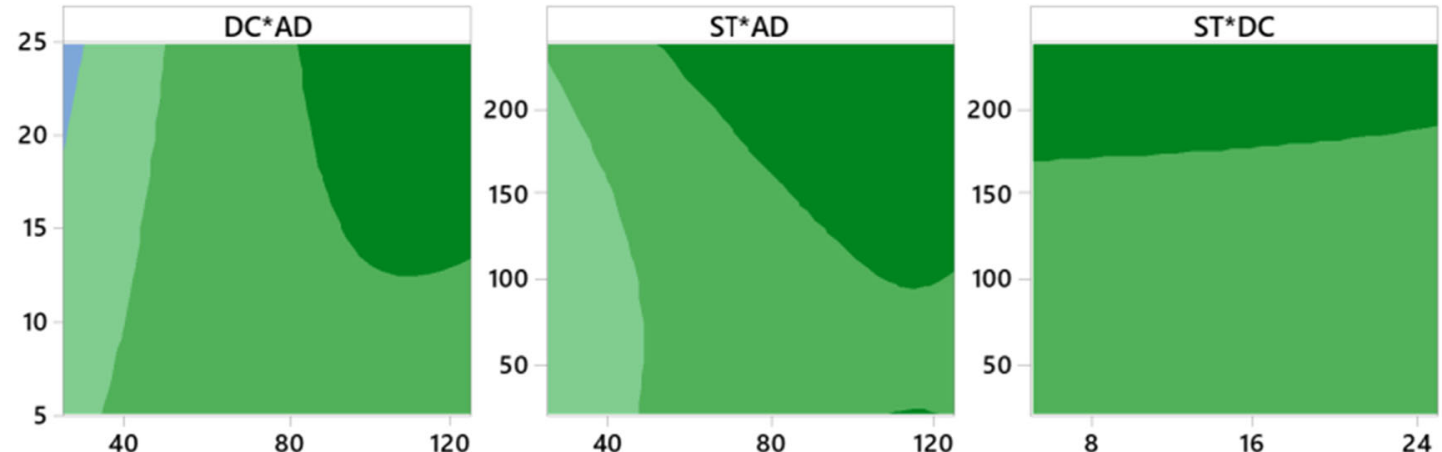

Surface Plots of \%R
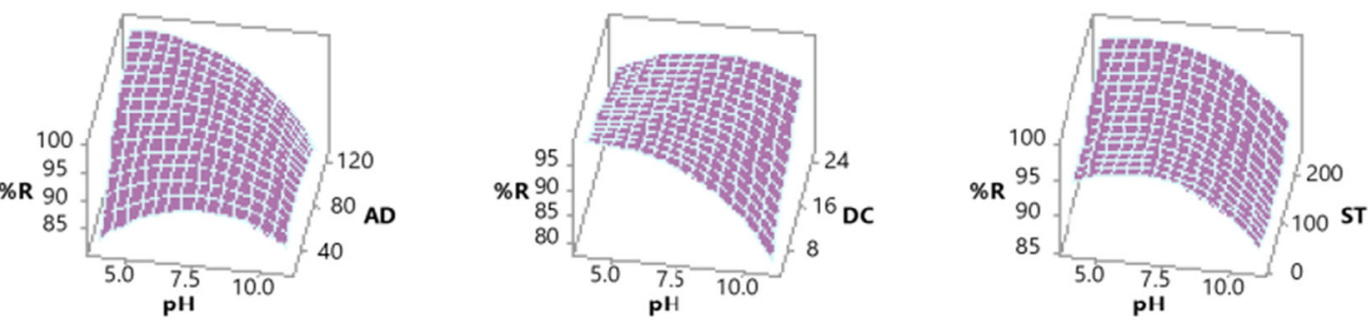

$\begin{array}{cc}\text { Hold Values } \\ \text { pH } & 7.5 \\ \text { AD } & 75 \\ \text { DC } & 15 \\ \text { ST } & 130\end{array}$
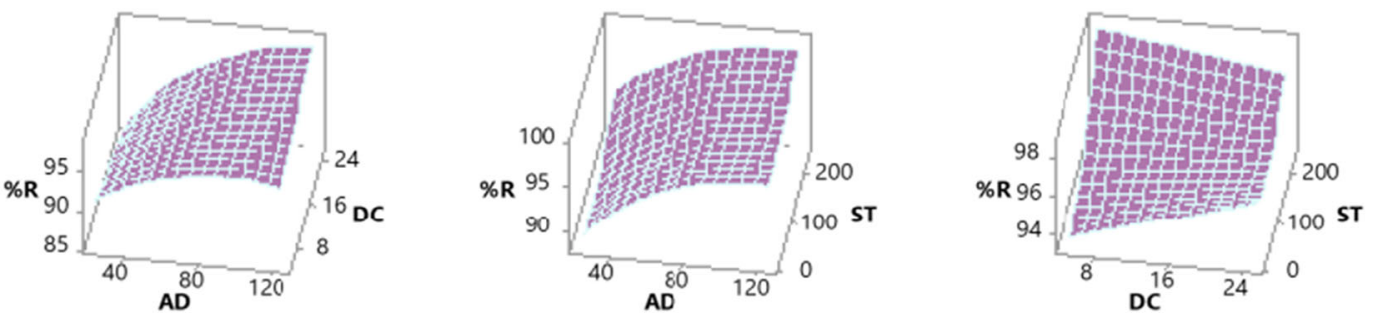

Fig. 3 Contour (upper panel) and surface (lower panel) plots of $\% R$

positively charged $\mathrm{NH}^{+}$moiety of $\mathrm{AO}$ (central phenyl ring) and the surface of the TTWM500 (El-Azazy et al. 2021; Karmakar et al. 2019; Sharma and Ilanchelian 2014).

Figure 7 shows the Raman spectra of raw as well as the biochars. Spectra of TTWM at both temperatures, and compared to the RWM, show significant D- and G-bands at 1351 and $1585 \mathrm{~cm}^{-1}$, respectively. Both bands are unique peaks in the spectra of carbonaceous materials. While the D-band reveals the carbon lattice properties such as defects and sizes (not the composition of the carbonaceous material), the Gband represents the stretching of C-C in the $s p^{2}$ system (Stankovich et al. 2007; Childres et al. 2013). Moreover, the 


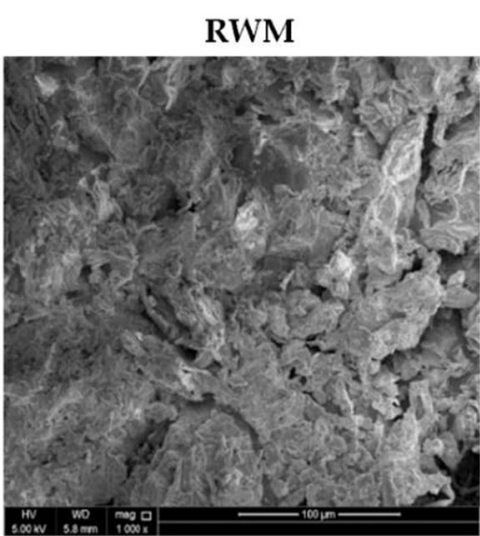

a

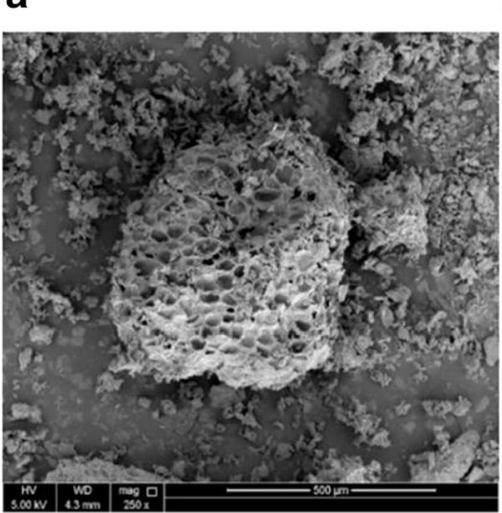

d

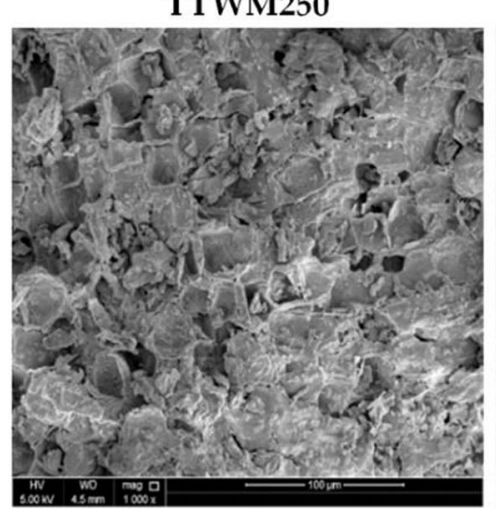

b

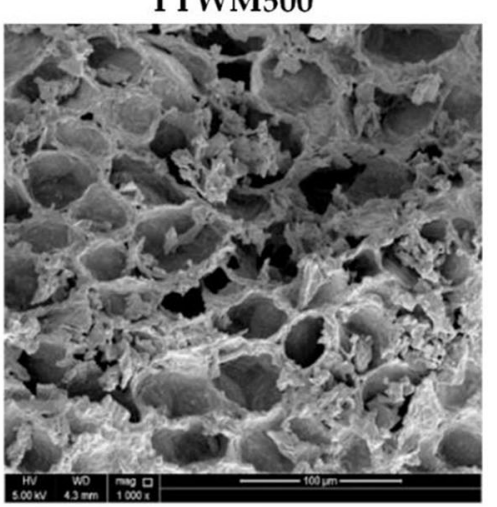

C

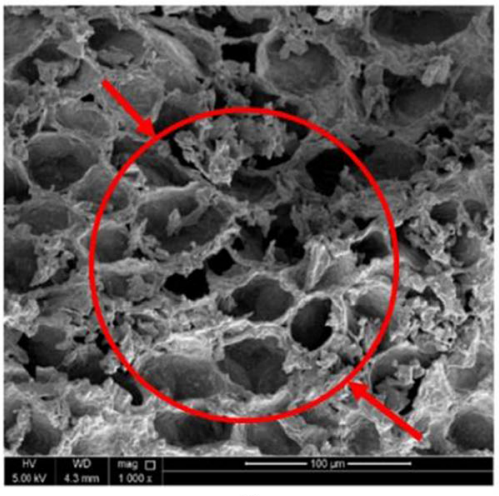

e

Fig. 4 SEM images of the three tested adsorbents $(\mathbf{a}$ RWM, b TTWM250, $\mathbf{c}$ TTWM500) at $\times 1000$ magnification, and $\mathbf{d}$ TTWM 500 $(\times 250)$ and $\mathbf{e}$ TTWM $500(\times 500)$

intensity ratio $I_{D}: I_{G}$ has increased from TTWM250 (0.77) to TTMW500 (1.053), which might have occurred due to the impact of thermal treatment on increasing the number of defects in the $s p^{2}$ plane of the carbon of biochars. Collected data prove the formation of carbonaceous materials with higher defects after thermal treatment compared to the raw sample.

\section{Thermo-gravimetric analysis (TGA)}

The data shown in Fig. 8 is the TGA analysis of RWM obtained under $\mathrm{N}_{2}$ and with a heating rate of $10{ }^{\circ} \mathrm{C} / \mathrm{min}$. The obtained data show that the weight loss in WMR samples has occurred over two main steps: (1) loss of physically adsorbed water in the range of at $25-130{ }^{\circ} \mathrm{C}$ and (2) between 150 and $800{ }^{\circ} \mathrm{C}$ where more than $50 \%$ of the sample is decomposed at this stage. This step is indicated by one large peak at $295^{\circ} \mathrm{C}$, a small peak at $727{ }^{\circ} \mathrm{C}$, and a shoulder at $193.5^{\circ} \mathrm{C}$ and could have occurred due to the decomposition of organic matter and the formation of thermally stable carbonaceous material (Chaudhari and Singhal 2015).

\section{Equilibrium isotherms}

Adsorption isotherm models were used to study the behavior of AO adsorption onto TTWM500. In this study, four models were used: Langmuir, Freundlich, Temkin, and DubininRadushkevich (D-R) (Benkaddour et al. 2018; Langmuir 1918; Guo and Wang 2019; Araújo et al. 2018; Moussavi and Barikbin 2010).

Figure $9 \mathrm{a}-\mathrm{f}$ and Table 6 show the obtained data for each of the proposed models employing both linear and nonlinear fitting. As shown in Table 6, and implementing the linear
Table 5 BET analysis of the three adsorbents

\begin{tabular}{lllll}
\hline Adsorbent & $\begin{array}{l}\text { BET surface } \\
\text { area }\left(\mathrm{m}^{2} / \mathrm{g}\right)\end{array}$ & $\begin{array}{l}\text { Langmuir surface } \\
\text { area }\left(\mathrm{m}^{2} / \mathrm{g}\right)\end{array}$ & Total pore volume $\left(\mathrm{cm}^{3} / \mathrm{g}\right)$ & Average pore radius $(\AA)$ \\
\hline RWM & 2.66 & 3.58 & 0.009 & 67.2 \\
TTWM250 & 2.93 & 4.11 & 0.010 & 70.4 \\
TTWM500 & 5.03 & 5.74 & 0.019 & 74.2 \\
\hline
\end{tabular}



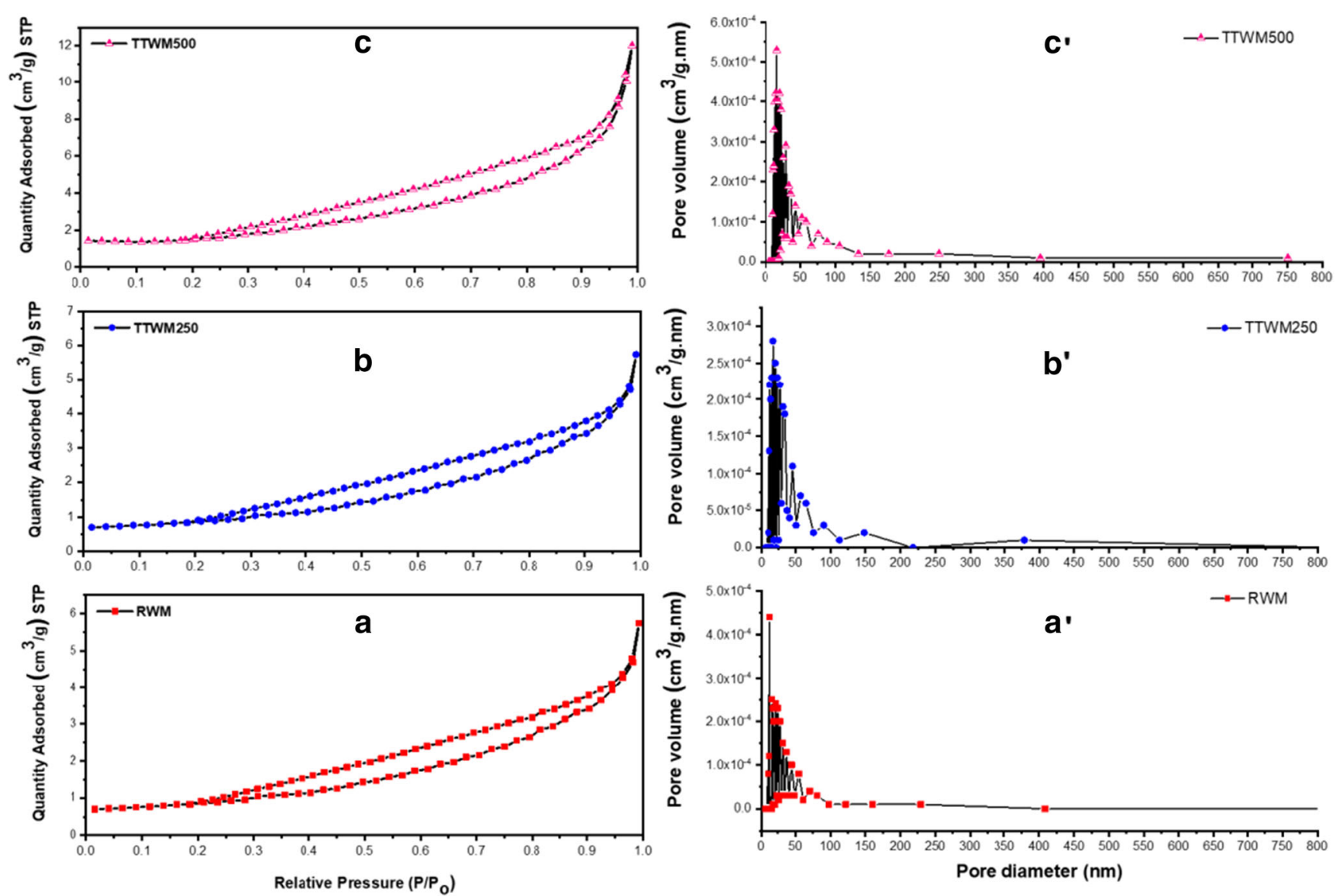

Fig. $5 \mathrm{~N}_{2}$ adsorption-desorption isotherms for the tested adsorbents

fitting, Freundlich model had the highest goodness-of-fit among the four isotherm models $\left(R^{2}\right.$, coefficient of determination value: 0.967 (Freundlich) $>0.965-0.952(\mathrm{D}-\mathrm{R})>\sim$ 0.944 (Temkin) $>0.910$ (Langmuir)), suggesting the occurrence of multilayer distribution of the $\mathrm{AO}$ onto the heterogenous surface of TTWM500 with an interaction among the AO molecules.

For Freundlich isotherm, the constants $K_{F}$ and $1 / n$ are indicators for the adsorbent capacity and change in the intensity of the adsorption as well as the deviation from linearity (Al-Saad et al. 2019). In general, when the value of $n$ is $>1$, the adsorption is favorable. Table 6 shows that the values of $n$ and $1 / n$, following linear fitting, are 2.098 and 0.477 , respectively, indicating that approximately $47 \%$ of adsorption took place on the active sites. By applying the nonlinear fitting, the values of $n$ and $1 / n$ were 1.724 and 0.58 at higher concentrations $(80$ to $400 \mathrm{mg} / \mathrm{L}$ ), while for the lower AO concentrations ( 5 to $80 \mathrm{mg} / \mathrm{L}$ ), $n$ and $1 / n$ were 2.941 and 0.34 , respectively. Therefore, it could be concluded that adsorption of AO onto TTWM500 was favorable at all concentrations.

The Langmuir model (Fig. 9a, e, f) suggests the occurrence of monolayer adsorption on the homogenous surface of the adsorbent. Moreover, it assumes the existence of finite number of adsorption sites and that no interaction is taking place between the adsorbate molecules. Langmuir model is used to obtain the maximum adsorption capacity $\left(q_{\max }\right)$. Table 6 shows that the value of $q_{\max }$ obtained from linear Langmuir (two linear segments) is $69.44 \mathrm{mg} / \mathrm{g}$ (compared to $63.95 \mathrm{mg} / \mathrm{g}$ using nonlinear fitting), suggesting monolayer coverage over homogenous adsorption sites within TTWM500. On the other hand, the $R_{L}$ value (separation factor) can be calculated using Eq. 5:

$$
R_{L}=\frac{1}{1+K_{L}\left(C_{0}\right)}
$$

In the above dimensionless equation, $K_{L}$ denotes the Langmuir isotherm constant (L.mole ${ }^{-1}$ ), while $C_{0}$ is the initial concentration $\left(\mathrm{mg} . \mathrm{L}^{-1}\right)$. The adsorption is favorable when $R_{L}$ 's value is between 0 and $1\left(0<R_{L}<1\right)$. However, if the $R_{L}$ value is $>1$, then the adsorption process is unfavorable. Also, the adsorption process is considered irreversible if the value of $R_{L}=0$. Consequently, the $R_{L}$ value measured for TTWM500 was $<1$ and $>0$, demonstrating favorable adsorption of AO onto TTWM500 (Langmuir 1918; Guo and Wang 2019). Yet, Langmuir isotherm could not be used to explain 

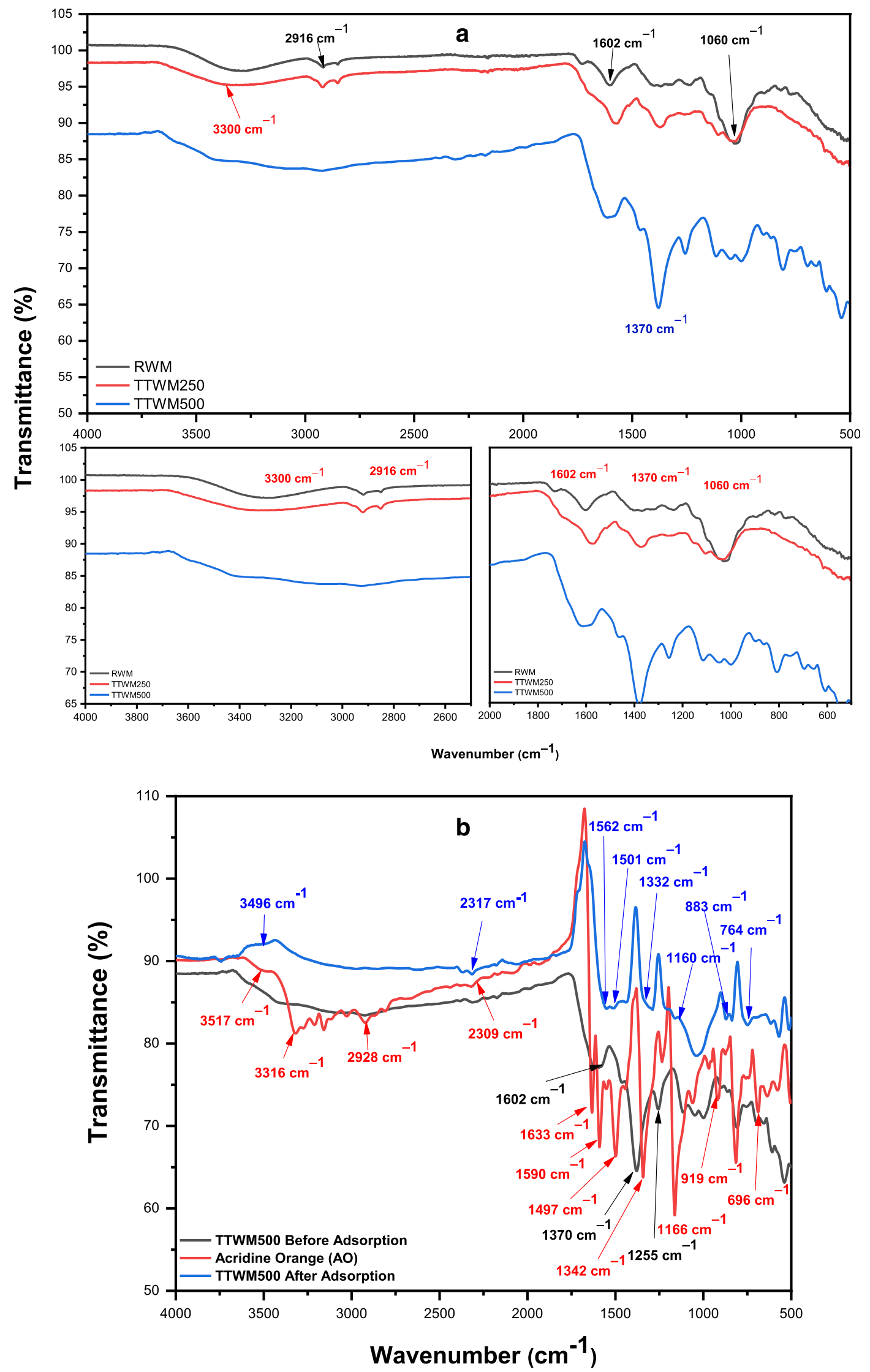

Fig. 6 a FT-IR spectra of the three adsorbents. b FT-IR spectra of the TTWM500 before and after adsorption of acridine orange (AO) 


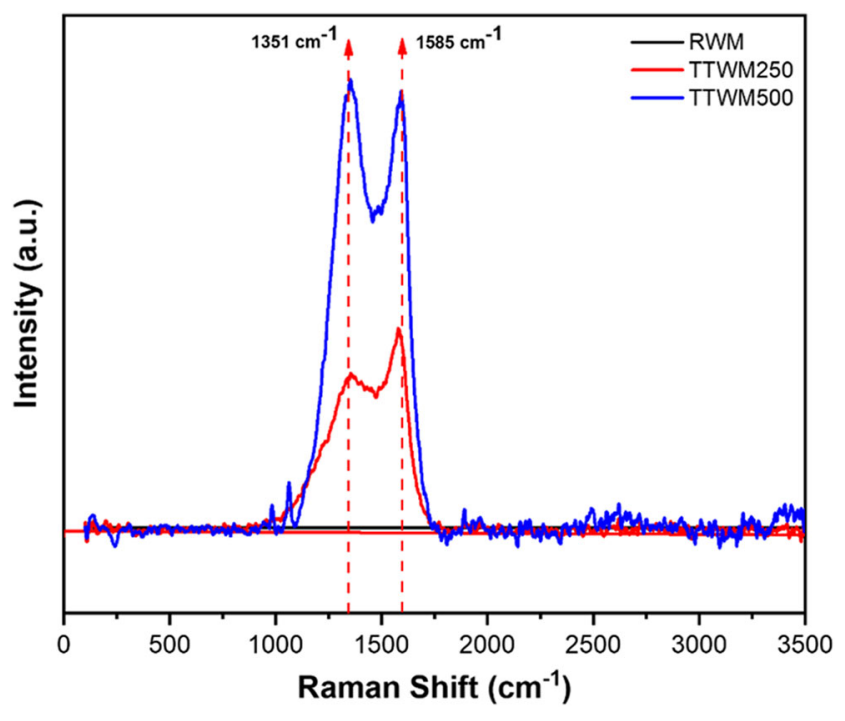

Fig. 7 Raman spectra of the three adsorbents

the overall adsorption of AO onto TTWM500 as indicated by the $R^{2}$ value.

Linear and nonlinear Temkin isotherms are shown in Fig. 9c, e, f. Temkin model is used to reflect the adsorbate-adsorbent interaction, where the heat of adsorption of the molecules in a layer decreases linearly with the adsorbate-adsorbent interactions. Table 6 shows that the sorption energy in linear Temkin isotherm at low $\mathrm{AO}$ concentrations was $864.8 \mathrm{~J} / \mathrm{mol}$ compared to $163.8 \mathrm{~J} / \mathrm{mol}$ at high concentration. For the nonlinear isotherm, the sorption energy at low and high concentrations of AO was 1813 and $222.8 \mathrm{~J} / \mathrm{mol}$, respectively.

Finally, the D-R isotherm (Fig. 9d-f) was utilized to identify the adsorption mechanism based on the free energy value. Physical adsorption occurs when free energy is $<8.0 \mathrm{~kJ} / \mathrm{mol}$, while chemical adsorption occurs when free energy is $>8.0$ $\mathrm{kJ} / \mathrm{mol}$. The free energy for adsorption of AO onto TTWM500, as revealed in Table 6, shows two types of adsorption mechanisms: the chemisorption mechanism (free

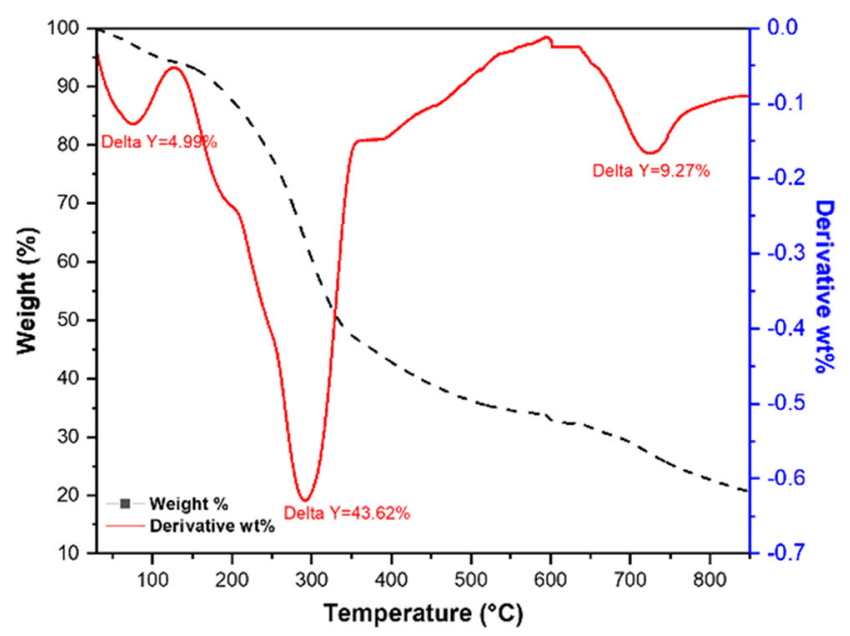

Fig. 8 TGA/dTGA analysis of RWM energy $=11.18 \mathrm{~kJ} / \mathrm{mol}$ for linear and $8.67 \mathrm{~kJ} / \mathrm{mol}$ for nonlinear model) at low concentrations of AO and physisorption (free energy $=4.08$ and $1.90 \mathrm{~kJ} / \mathrm{mol}$ for linear and nonlinear models, respectively) at high concentrations of AO. This finding shows that the adsorption of AO onto TTWM500 runs over two stages; the first stage could be attributed to chemical adsorption to form one layer. The second could be attributed to the physical interactions to form multilayers. The $q_{\max }$ for the low concentration region was 12.89 and $7.03 \mathrm{mg} / \mathrm{g}$ for the linear and nonlinear models, respectively. At high concentration, the $q_{\max }$ was 50.28 and $43.07 \mathrm{mg} / \mathrm{g}$ for both models.

All in all, adsorption of AO onto TTWM500 agreed well with Freundlich isotherm. However, prevalence of multilayer adsorption might not be the exclusive mechanism. Taking into consideration the findings of adsorbents' characterization, output of BB design, and the results of the equilibrium study, adsorption of AO onto TTWM500 can be better described. As per the findings of the D-R isotherm, adsorption of $\mathrm{AO}$ onto TTWM500 follows two patterns depending on the DC. Occurrence of chemisorption at low AO concentrations could be explained considering both the nature of $\mathrm{AO}$ under the experimental conditions and the adsorbent structure as revealed by FT-IR, SEM, and BET analyses. At low concentrations of the dye, the adsorption of a monolayer of $\mathrm{AO}$ onto the surface of TTWM500 and the fixation of the dye inside the adsorbent pores via hydrogen bonding (through the nitrogen moieties in AO) and electrostatic interactions is probably the mechanism. On the other hand, AO possesses a conjugated system (Scheme 1). As per Raman spectroscopic analysis, the biochar, TTWM500 has a graphene like structure with $s p^{2}$ system. These findings corroborate the occurrence of $\pi-\pi$ electron donor-acceptor (EDA) interactions between $\mathrm{AO}$ and the carbonaceous adsorbent.

As per the BET analysis, the surface area of TTWM500 is low, an issue that could not support the achieved $\% R$ and $q_{e}$ values. However, the porous structure of the carbonaceous adsorbent could be the justification. The presence of mesopores and macropores with an advanced intra- and multilayered pore structure on the surface of TTWM500 could explain the subsequent physical interactions to form multilayers. This finding comes in alignment with the equilibrium isotherm finding where Freundlich isotherm was a perfect fit to explain the adsorption behavior of AO onto TTWM500.

\section{Kinetic studies}

The kinetics of the adsorption of AO dye onto TTWM500 was studied using linear and nonlinear fitting of the following models: pseudo-first order (PFO), pseudo-second order (PSO), Elovich, and Weber-Morris (WM) (Benkaddour et al. 2018; Hameed et al. 2009). The linear kinetic models in Figs. 10a and 10b show a representation of $\ln \left(q_{e}-q_{t}\right)$ and time $/ q_{t}$ versus time and for the PFO and PSO kinetic models. 
Table 6 General equations of Langmuir, Freundlich, Temkin, and Dubinin-Radushkevich (D-R) isotherms for the adsorption of AO onto TTWM500 and their fitting parameters

\begin{tabular}{|c|c|c|c|c|}
\hline \multirow[t]{2}{*}{ Model } & \multirow[t]{2}{*}{ Type and model equation } & \multirow[t]{2}{*}{ Parameter } & \multicolumn{2}{|l|}{$\mathrm{DC}(\mathrm{mg} / \mathrm{L})$} \\
\hline & & & $5-80$ & $80-400$ \\
\hline \multirow[t]{6}{*}{ Langmuir } & Linear & $q_{\max }\left(\mathrm{mg} \cdot \mathrm{g}^{-1}\right)$ & 11.05 & 69.44 \\
\hline & \multirow{2}{*}{$\frac{C_{e}}{q_{e}}=\frac{1}{q_{m} K_{L}}+\frac{C_{e}}{q_{m}}$} & $K_{L}\left(\mathrm{~L} \cdot \mathrm{mole}^{-1}\right)$ & 0.99 & 0.01 \\
\hline & & $R^{2}$ & 0.954 & 0.910 \\
\hline & Nonlinear & $q_{\max }\left(\mathrm{mg} \cdot \mathrm{g}^{-1}\right)$ & 7.90 & 63.95 \\
\hline & \multirow{2}{*}{$q_{e}=\frac{q_{m} K_{L} C_{e}}{1+K_{L} C_{e}}$} & $K_{L}\left(\right.$ L.mole $\left.{ }^{-1}\right)$ & 3.47 & 0.016 \\
\hline & & $R^{2}$ & 0.965 & 0.953 \\
\hline \multirow[t]{6}{*}{ Freundlich } & \multirow{3}{*}{$\begin{array}{l}\text { Linear } \\
\log \left(q_{e}\right)=\log \left(K_{F}\right)+\left(\frac{1}{n}\right) \log \left(C_{e}\right)\end{array}$} & $K_{F}($ mole $/ \mathrm{g})(\mathrm{L} / \mathrm{mole})^{1 / n}$ & 4.02 & \\
\hline & & $1 / n$ & 0.477 & \\
\hline & & $R^{2}$ & 0.967 & \\
\hline & Nonlinear & $K_{F}(\mathrm{~mole} / \mathrm{g})(\mathrm{L} / \mathrm{mole})^{1 / n}$ & 4.68 & 2.74 \\
\hline & \multirow{2}{*}{$q_{e}=K_{F} C_{e}^{\frac{1}{n}}$} & $1 / n$ & 0.34 & 0.58 \\
\hline & & $R^{2}$ & 0.972 & 0.985 \\
\hline \multirow[t]{6}{*}{ Temkin } & Linear & $\mathrm{b}_{T}(\mathrm{~J} / \mathrm{mole})$ & 864.8 & 163.8 \\
\hline & \multirow{2}{*}{$q_{e}=\frac{R T}{b_{T}} \ln \left(A_{T}\right)+\frac{R T}{b_{T}} \ln \left(C_{e}\right)$} & $\mathrm{A}_{T}(\mathrm{~L} / \mathrm{mole})$ & 4.65 & 0.136 \\
\hline & & $R^{2}$ & 0.943 & 0.944 \\
\hline & Nonlinear & $\mathrm{b}_{T}(\mathrm{~J} / \mathrm{mole})$ & 1813.8 & 222.81 \\
\hline & \multirow{2}{*}{$q_{e}=\frac{R T}{b_{T}} \ln \left(A_{T} C_{e}\right)$} & $\mathrm{A}_{T}(\mathrm{~L} / \mathrm{mole})$ & 56.79 & 0.271 \\
\hline & & $R^{2}$ & 0.958 & 0.911 \\
\hline \multirow[t]{9}{*}{$\mathrm{D}-\mathrm{R}$} & \multirow{2}{*}{$\begin{array}{l}\text { Linear } \\
\ln \left(q_{e}\right)=\ln \left(q_{s}\right)-\beta \epsilon^{2}\end{array}$} & $B$ & $4 \times 10^{-9}$ & $3 \times 10^{-8}$ \\
\hline & & $\mathrm{E}(\mathrm{kJ} / \mathrm{mole})$ & 11.18 & 4.08 \\
\hline & \multirow{2}{*}{$\epsilon=R T\left(1+\frac{1}{C_{e}}\right)$} & $\mathrm{q}_{s}(\mathrm{mg} / \mathrm{g})$ & 12.89 & 50.28 \\
\hline & & $R^{2}$ & 0.965 & 0.952 \\
\hline & \multicolumn{4}{|l|}{$E=1 / \sqrt{2 \beta}$} \\
\hline & \multirow{4}{*}{$\begin{array}{l}\text { Nonlinear } \\
q_{e}=q_{s} . \exp \left(-\beta \cdot \epsilon^{2}\right)\end{array}$} & $B$ & $6.64 \times 10^{-9}$ & $1.39 \times 10^{-6}$ \\
\hline & & $\mathrm{E}(\mathrm{kJ} /$ mole $)$ & 8.67 & 1.90 \\
\hline & & $\mathrm{q}_{s}(\mathrm{mg} / \mathrm{g})$ & 7.03 & 43.07 \\
\hline & & $R^{2}$ & 0.899 & 0.835 \\
\hline
\end{tabular}

$q_{e}$, amount of adsorbate in the adsorbent at equilibrium; $K_{L}$, Langmuir isotherm constant; $q_{\max }$, maximum monolayer coverage capacities; $K_{F}$, Freundlich adsorption constant; $\boldsymbol{C}_{e}$ equilibrium concentration; $q_{s}$, theoretical isotherm saturation capacity; $A_{T}$, Temkin isotherm equilibrium binding constant; $R$, universal gas constant $(8.314 \mathrm{~J} / \mathrm{mol} \mathrm{K}) ; T$ is the temperature $(\mathrm{K}) ; b_{T}$, Temkin isotherm constant

According to the data presented in Table 7 and by comparing the $R^{2}$ values for the four models, adsorption of $\mathrm{AO}$ onto the studied adsorbent could be best described using the PSO model, where the $R^{2}=1.000$. The nonlinear fitting (Fig. 10e, f) shows similar data to the linear models with the highest $R^{2}$ value (0.976) being obtained for PSO at reaction time between 10 and $30 \mathrm{~min}$. Therefore, the adsorption reaction according to the linear models could be represented as follows:

$\mathrm{AO}+\operatorname{TTWM} 500(\stackrel{k}{\rightarrow})$ AO-TTWM500

Accordingly, the rate of the reaction $=k[\mathrm{AO}][$ TTWM500], indicating that the adsorption rate depends on both the adsorbate and the adsorbent. In addition, the adsorbed quantity determined from the nonlinear model was between 46.54 and $48.67 \mathrm{mg} / \mathrm{g}$, similar to the obtained data from the equilibrium isotherms.

The Weber-Morris (WM) intraparticle diffusion model (Fig. 10c, e, f) reveals significant findings, where, besides the intra-particle diffusion, there is another mechanism that controls the diffusion of AO. According to the calculated parameters in Table 7 from linear and nonlinear models, diffusion occurs over two stages. The adsorption reaction commenced with a high intraparticle diffusion rate (1.127 $\left.\mathrm{mg} . \mathrm{g}^{-1} \cdot \mathrm{min}^{-0.5}\right)$ with high boundary layer thickness (43.17 $\mathrm{mg} / \mathrm{g}$ ). The intraparticle diffusion rate decreased with time (0.3113 and $0.535 \mathrm{mg}$. $\mathrm{g}^{-1} \cdot \mathrm{min}^{-0.5}$ for linear and nonlinear 

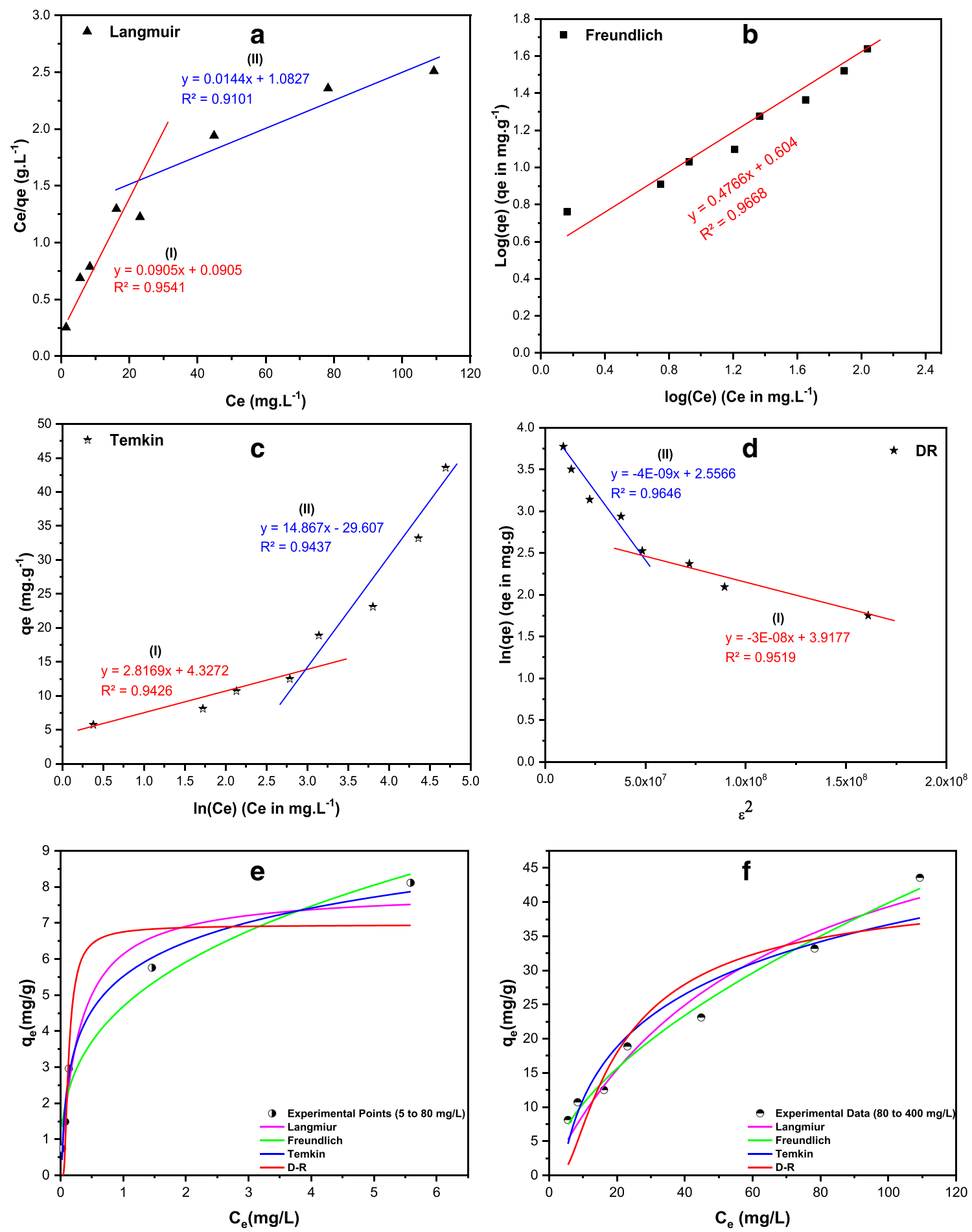

Fig. 9 Adsorption linear models of AO onto TTWM500 including Langmuir (a), Freundlich (b), Temkin (c), DR (d), and nonlinear models at low (e) and high $\mathrm{AO}$ concentrations (f)

fittings, respectively) when the boundary layer became 46.27 and $45.17 \mathrm{mg} / \mathrm{g}$ for linear and nonlinear models, respectively. On the other hand, in the Elovich model (Fig. 10d-f), the initial adsorption of AO onto TTWM500 was very high in the case of both fittings and equals $3.7 \times 10^{15} \mathrm{mg} \cdot \mathrm{g}^{-1} \cdot \mathrm{min}^{-1}$ for linear models, and the nonlinear model ranged between 6.9 $\times 10^{17}$ and $4.9 \times 10^{16} \mathrm{mg} \cdot \mathrm{g}^{-1} \cdot \mathrm{min}^{-1}$, justifying the elevated adsorption efficiency of TTWM500. 
Table 7 The kinetics study results corresponding to the data shown in Fig. 10

\begin{tabular}{|c|c|c|c|c|}
\hline \multirow[t]{2}{*}{ Model } & \multirow[t]{2}{*}{ Type and model equation } & \multirow[t]{2}{*}{ Parameter } & \multicolumn{2}{|l|}{ Time (min) } \\
\hline & & & $0-10$ & $10-30$ \\
\hline \multirow[t]{6}{*}{ PFO } & \multirow{3}{*}{$\begin{array}{l}\text { Linear } \\
\ln \left(q_{e}-q_{t}\right)=\ln \left(q_{e}\right)-k_{1} t\end{array}$} & $K_{1}\left(\min ^{-1}\right)$ & 0.011 & 0.002 \\
\hline & & $q_{e}(\mathrm{mg} / \mathrm{g})$ & 36.60 & 34.17 \\
\hline & & $R^{2}$ & 0.963 & 0.838 \\
\hline & Nonlinear & $K_{1}\left(\min ^{-1}\right)$ & 3.207 & 0.369 \\
\hline & \multirow{2}{*}{$\frac{d q_{t}}{d t}=k_{1}\left(q_{e}-q_{t}\right)$} & $q_{e}(\mathrm{mg} / \mathrm{g})$ & 45.90 & 47.80 \\
\hline & & $R^{2}$ & 0.589 & 0.937 \\
\hline \multirow[t]{6}{*}{ PSO } & Linear & $K_{2}\left(\mathrm{~g} \cdot \mathrm{mg}^{-1} \cdot \mathrm{min}^{-1}\right)$ & 0.075 & \\
\hline & \multirow{2}{*}{$\frac{t}{q e}=\frac{1}{k_{2} q_{e}^{2}}+\frac{1}{q_{e}} t$} & $q_{e}(\mathrm{mg} / \mathrm{g})$ & 48.31 & \\
\hline & & $R^{2}$ & 1.000 & \\
\hline & Nonlinear & $K_{2}\left(\mathrm{~g} \cdot \mathrm{mg}^{-1} \cdot \mathrm{min}^{-1}\right)$ & 0.3565 & 0.049 \\
\hline & \multirow{2}{*}{$\frac{d q_{t}}{d t}=k_{2}\left(q_{e}-q_{t}\right)^{2}$} & $q_{e}(\mathrm{mg} / \mathrm{g})$ & 46.54 & 48.67 \\
\hline & & $R^{2}$ & 0.908 & 0.976 \\
\hline \multirow[t]{6}{*}{ Elovich } & Linear & $\alpha$ & $3.7 \times 10^{15}$ & \\
\hline & \multirow{2}{*}{$q_{t}=\frac{1}{\beta} \ln (\alpha \beta)+\frac{1}{\beta} \ln (t)$} & $\beta$ & 0.812 & \\
\hline & & $R^{2}$ & 0.983 & \\
\hline & \multirow{3}{*}{$\begin{array}{l}\text { Nonlinear } \\
q_{t}=\frac{1}{\beta} \times \ln (1+\alpha \beta t)\end{array}$} & $\alpha$ & $6.9 \times 10^{17}$ & $4.9 \times 10^{16}$ \\
\hline & & $\beta$ & 0.930 & 0.867 \\
\hline & & $R^{2}$ & 0.909 & 0.925 \\
\hline \multirow[t]{6}{*}{ WM } & \multirow{3}{*}{$\begin{array}{l}\text { Linear } \\
q_{t}=K_{I} t^{0.5}+C\end{array}$} & $K_{I}$ & 1.127 & 0.311 \\
\hline & & $C$ & 43.17 & 46.27 \\
\hline & & $R^{2}$ & 0.967 & 0.993 \\
\hline & \multirow{3}{*}{$\begin{array}{l}\text { Nonlinear } \\
q_{t}=K_{I} t^{0.5}+C\end{array}$} & $K_{I}$ & 1.127 & 0.535 \\
\hline & & $C$ & 43.17 & 45.17 \\
\hline & & $R^{2}$ & 0.967 & 0.883 \\
\hline
\end{tabular}

where $q_{t}$ is adsorbed quantity at time $t$; while $\alpha$ and $\beta$ are initial sorption concentration rate $\left(\mathrm{mg} \mathrm{g}^{-1} \cdot \mathrm{min}^{-1}\right.$ ) and desorption constant (g/mg), $K_{I}$ is intraparticle diffusion rate constant $\left(\mathrm{mg} \cdot \mathrm{g}^{-1} \cdot \mathrm{min}^{-0.5}\right)$, and $C$ is boundary thickness effect

\section{Desorption and regeneration studies}

Adsorbent regeneration and reusability represent the most important aspects of the adsorption study. In other words, and to make the adsorption process efficient and cost-effective, it is crucial to reuse the adsorbent following multiple sorption/ desorption cycles (Singh and Singhal 2015). For this purpose, a desorption study with six different eluents was conducted, followed by six consecutive sorption-desorption cycles. The obtained data (Fig. 11a) show a comparison between the utilized eluents and their corresponding desorption efficiency (\%). As per the shown data, $0.1 \mathrm{M} \mathrm{NaOH}$ had the highest desorption efficiency of $75.90 \%$, followed by $0.1 \mathrm{M} \mathrm{H}_{2} \mathrm{SO}_{4}$, which showed a desorption efficiency of $46.65 \%$. On the other hand, $\mathrm{H}_{2} \mathrm{O}$ and $0.1 \mathrm{M} \mathrm{HNO}_{3}$ showed the lowest desorption efficiency $(2.31 \%$ and $11.46 \%$, respectively). Therefore, $0.1 \mathrm{M} \mathrm{NaOH}$ was used as the most suitable desorbing agent.

For the adsorbent regeneration, the cyclic sorptiondesorption findings shown in Fig. 11b illustrate that the dye removal efficiency has decreased slightly from $99.45 \%$ (cycle 1) to $87.15 \%$ (cycle 6), probably due to the incomplete desorption and removal of $\mathrm{AO}$ from the active adsorption sites. The average AO removal efficiency was around $87 \%$ over the six consecutive regeneration cycles. The obtained results reveal an excellent reusability of TTWM500 and the possibility of its regeneration even after a larger number of cycles.

\section{Conclusions}

Watermelon rinds (WMR) have been developed and effectively utilized as a green, low-cost, non-conventional adsorbent to remove AO dye from contaminated water samples. Both raw and thermally treated rinds at 250 and $500{ }^{\circ} \mathrm{C}$ were tested for AO removal, and TTWM500 showed the best adsorption efficiency. The effect of four different variables, namely $\mathrm{pH}, \mathrm{AD}, \mathrm{DC}$, and ST on the removal efficiency of TTWM500 was tested. The Box-Behnken design was applied 

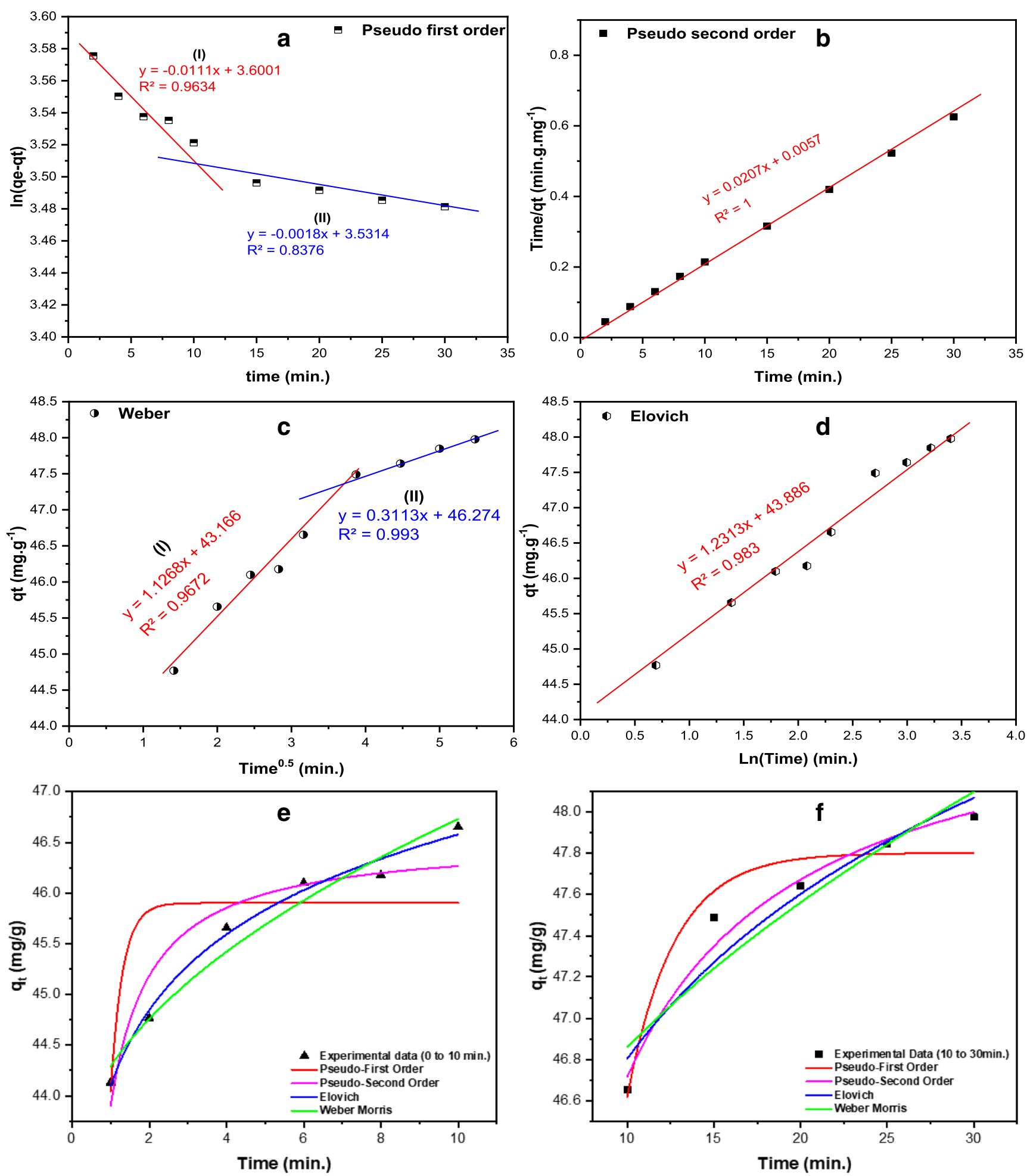

Fig. 10 Kinetic models for the adsorption of AO onto TTWM500. The panels a-d show the linear fitting of data: a Pseudo-first order (PFO), b Pseudo-second order, $\mathbf{c}$ Weber-Morris (WM), and d Elovich. The panels

e, and $\mathbf{f}$ show the nonlinear fitting of data between: e 0-10 min and $\mathbf{f} 10-30$ $\min$

were characterized using FT-IR, Raman, BET, SEM, and TGA analyses. The obtained data showed that the surface area of TTWM500 was the highest among the tested adsorbents 

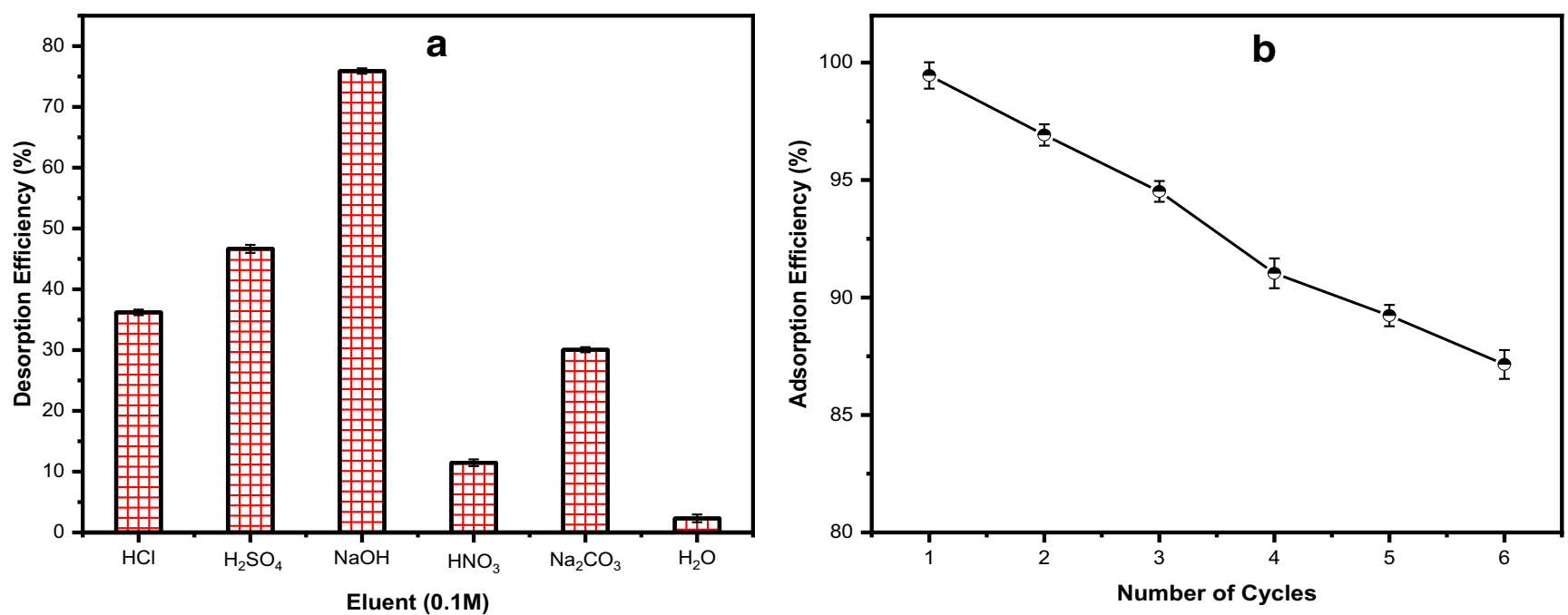

Fig. 11 a Effect of eluent type on the AO desorption and $\mathbf{b}$ the regeneration performance of the TTWM500 adsorbent towards AO (using $0.1 \mathrm{M}$ NaOH as an eluent for 6 cycles)

$\left(5.03 \mathrm{~m}^{2} / \mathrm{g}\right)$, and the SEM micrographs showed the presence of large pores in the TTWM500 sample. Furthermore, the FTIR analysis before and after adsorption showed the alterations in intensities, shifts in position, and even complete disappearance of some functional groups confirming the interaction of $\mathrm{AO}$ and the adsorbent. Equilibrium studies using linear and nonlinear fittings showed that data fit well to Freundlich isotherm and that adsorption is favorable with a maximum adsorption capacity of $69.44 \mathrm{mg} / \mathrm{g}$ from the linear fitting Langmuir equation. Besides, the adsorption is chemisorption and physisorption at low and high AO concentrations, respectively. The kinetic studies showed that the adsorption occurred over two stages with a high intraparticle diffusion rate (1.127 $\left.\mathrm{mg} \cdot \mathrm{g}^{-1} \cdot \min ^{-0.5}\right)$ and high boundary layer thickness (43.17 $\mathrm{mg} / \mathrm{g}$ ). The desorption study showed that TTWM500 could be regenerated with the adsorption efficiency being preserved up to $87 \%$ after six cycles.

Supplementary Information The online version contains supplementary material available at https://doi.org/10.1007/s11356-021-13652-9.

Acknowledgements Open Access funding provided by the Qatar National Library. The project members would like to extend their special thanks to the Central Lab Unit (CLU) at Qatar University.

Author contribution Ahmed S. El-Shafie (A.S.-E.), Siham S. Hassan (S.S.H.), Nuri Akhter (N.A.), Marwa El-Azazy (M.E-A.), Conceptualization, M.E-A.; methodology, M.E-A.; software, M.E-A.; validation, M.E-A., A.S.-E., and S.S.H.; formal analysis, M.E-A. and A.S.-E.; investigation, M.E-A., A.S.-E., and S.S.H.; N.A.; resources, M.E-A.; data curation, M.E-A., A.S.-E., and S.S.H.; N.A.; writing - original draft preparation, M.E-A., A.S.-E., and S.S.H.; N.A.; writing - review and editing, M.E-A., A.S.-E., and S.S.H.; visualization, M.E.-A., S.S.H., and A.S.-E.; supervision, M.E.-A.; project administration, M.E-A.

Funding Open access funding provided by the Qatar National Library.
Data availability All data used to support the findings of this study are included within the article.

\section{Declarations}

Ethics approval Not applicable.

Consent to participate Not applicable.

Consent to publish Not applicable.

Competing interests The authors declare no competing interests.

Open Access This article is licensed under a Creative Commons Attribution 4.0 International License, which permits use, sharing, adaptation, distribution and reproduction in any medium or format, as long as you give appropriate credit to the original author(s) and the source, provide a link to the Creative Commons licence, and indicate if changes were made. The images or other third party material in this article are included in the article's Creative Commons licence, unless indicated otherwise in a credit line to the material. If material is not included in the article's Creative Commons licence and your intended use is not permitted by statutory regulation or exceeds the permitted use, you will need to obtain permission directly from the copyright holder. To view a copy of this licence, visit http://creativecommons.org/licenses/by/4.0/.

\section{References}

Abbas AF, Ahmed MJ (2016) Mesoporous activated carbon from date stones (Phoenix dactylifera L.) by one-step microwave assisted $\mathrm{K}_{2} \mathrm{CO}_{3}$ pyrolysis. J Water Process Eng 9:201-207. https://doi.org/ 10.1016/j.jwpe.2016.01.004

Alexander J, Jayanthi G, Lakshmipathy R, Kulasekaran A, Andal V (2015) Colour removal studies on treatment of textile dyeing effluent by chitosan modified watermelon rind composite (CWR). Int $\mathbf{J}$ ChemTech Res 8:10-15

Al-Saad K, El-Azazy M, Issa AA, Al-Yafie A, El-Shafie AS, Al-Sulaiti M, Shomar B (2019) Recycling of date pits into a green adsorbent for removal of heavy metals: a fractional factorial design-based 
approach. Front Chem 7(552):1-16. https://doi.org/10.3389/fchem. 2019.00552

Antony J (2003) Design of experiments for engineers and scientists, 1st ed.; Antony J (ed) Elsevier: Amsterdam, The Netherlands, pp. 6-16

Araújo CST, Almeida ILS, Rezende HC, Marcionilio SMLO, Léon JJL, de Matos TN (2018) Elucidation of mechanism involved in adsorption of $\mathrm{Pb}$ (II) onto Lobeira fruit (Solanum lycocarpum) using Langmuir, Freundlich and Temkin isotherms. Microchem J 137: 348-354. https://doi.org/10.1016/j.microc.2017.11.009

Basu N, Pratibha N, Nisha S (2014) Decolourization of synthetic dyes using eco-friendly fruit and vegetable peel adsorbents. Int J Sci Res 3:1490-1493

Benkaddour S, Slimani R, Hiyane H, El Ouahabi I, Hachoumi I, El Antri S, Lazar S (2018) Removal of reactive yellow 145 by adsorption onto treated watermelon seeds: Kinetic and isotherm studies. Sustain Chem Pharm 10:16-21. https://doi.org/10.1016/j.scp.2018.08.003

Box GEP, Cox DR (1964) An analysis of transformations. J R Stat Soc Ser B Stat Methodol B26:211-252

Bruns RE, Scarminio IS, Neto BB (2006) Statistical designchemometrics, 1st edn. Elsevier, Amsterdam, The Netherlands

Camargo FP, Tonello PS, Alves dos Santos AC, Duarte ICS (2016) Removal of toxic metals from sewage sludge through chemical, physical, and biological treatments - a review. Water Air Soil Pollut 227:433. https://doi.org/10.1007/s11270-016-3141-3

Chaudhari SA, Singhal RS (2015) Cutin from watermelon peels: a novel inducer for cutinase production and its physicochemical characterization. Int J Biol Macromol 79:398-404. https://oi.org/10.1016/j. ijbiomac.2015.05.006

Chen X, Lin Q, He R, Zhao X, Li G (2017) Hydrochar production from watermelon peel by hydrothermal carbonization. Bioresour Technol 24:236-243. https://doi.org/10.1016/j.biortech.2017.04.012

Childres I, Jauregui LA, Park W, Cao H, Chen YP (2013) Raman spectroscopy of graphene and related materials in New developments in photon and materials research. 1st ed.; Jang JI (ed) Nova Science Publishers: Oxford, UK, 1:403-418

Elazazy MS (2017) Factorial design and machine learning strategies: impacts on pharmaceutical analysis. In: Zafar F (ed) Spectroscopic analyses. IntechOpen. DOI: 10.5772/intechopen.69891. Available from: https://www.intechopen.com/books/spectroscopic-analysesdevelopments-and-applications/factorial-design-and-machinelearning-strategies-impacts-on-pharmaceutical analysis.

Elazazy MS, El-Hamshary M, Sakr M, Al-Easa HS (2018) PlackettBurman and Box-Behnken designs as chemometric tools for micro-determination of L-Ornithine. Spectrochim Acta A Mol Biomol Spectrosc 193:397-406. https://doi.org/10.1016/j.saa.2017. 12.044

El-Azazy M, El-Shafie AS, Ashraf A, Issa AA (2019a) Eco-structured biosorptive removal of basic fuchsin using pistachio nutshells: a definitive screening design — based approach. Appl Sci 9(22): 4855. https://doi.org/10.3390/app9224855

El-Azazy M, Dimassi S, El-Shafie A, Issa A (2019b) Bio-waste aloe vera leaves as an efficient adsorbent for titan yellow from wastewater: structuring of a novel adsorbent using Plackett-Burman factorial design. Appl Sci 9(22):4856. https://doi.org/10.3390/app9224856

El-Azazy M, Kalla RN, Issa AA, Al-Sulaiti M, El-Shafie AS, Shomar B, Al-Saad K (2019c) Pomegranate peels as versatile adsorbents for water purification: application of Box-Behnken design as a methodological optimization approach. Environ Prog Sustain Energy 38(6):13223. https://doi.org/10.1002/ep.13223

El-Azazy M, El-Shafie AS, Issa AA, Al-Sulaiti M, Al-Yafie J, Shomar B, Al-Saad K (2019d) Potato peels as an adsorbent for heavy metals from aqueous solutions: eco-structuring of a green adsorbent operating Plackett-Burman design. J Chemother 2019(4926240):1-14. https://doi.org/10.1155/2019/4926240

El-Azazy M, El-Shafie AS, El-Gendy A, Issa A, Al-Meer S, Al-Saad K (2020) A comparison between different agro-wastes and carbon nanotubes for removal of sarafloxacin from wastewater: kinetics and equilibrium studies. Molecules 25:5429. https://doi.org/10. 3390/molecules25225429

El-Azazy M, El-Shafie AS, Al-Meer S, Al-Saad KA (2021) Ecostructured adsorptive removal of tigecycline from wastewater: date pits' biochar versus the magnetic biochar. Nanomaterials 11(1):30. https://doi.org/10.3390/nano11010030

El-Gendy A, El-Shafie AS, Issa AA, Al-Meer S, Al-Saad K, El-Azazy M (2020) Carbon-based materials (CBMs) for remediation and determination of antimicrobials in different substrates: wastewater and infant foods as examples. In: Bartoli M (ed) Carbon based material for environmental protection and remediation. IntechOpen, DOI: 10.5772/intechopen.91750. Available from: https://www. intechopen.com/books/carbon-based-material-for-environmentalprotection-and-remediation/carbon-based-materials-cbms-fordetermination-and-remediation-of-antimicrobials-in-differentsubstra

Elmoubarki R, Taoufik M, Moufti A, Tounsadi H, Mahjoubi FZ, Bouabi Y, Qourza S, Abdennouri M, Barka N (2017) Box-Behnken experimental design for the optimization of methylene blue adsorption onto Aleppo pinecones. J Mater Environ Sci 8:2184-2191

Forgacs E, Cserháti T, Oros G (2004) Removal of synthetic dyes from wastewaters: a review. Environ Int 30:953-971. https://oi.org/10. 1016/j.envint.2004.02.001

Geaniyu SO, Hullebusch EDV, Cretin M, Esposito G, Oturan MA (2015) Coupling of membrane filtration and advanced oxidation processes for removal of pharmaceutical residues: a critical review. Sep Purif Technol 15:891-914. https://doi.org/10.1016/j.seppur.2015.09.059

Ghaly AE, Ananthashankar R, Alhattab M, RamakrishnaVV (2014) Production, characterization and treatment of textile effluents: a critical review. JChem Eng Process Technol 5:1-18. https://doi.org/10. 4172/2157-7048.1000182

Gleick P, Iceland C (2018) Water, security, and conflict. World Resources Institute. https://www.wri.org/publication/watersecurity-and-conflict. Accessed 24 November 2020

Guo X, Wang J (2019) Comparison of linearization methods for modeling the Langmuir adsorption isotherm. J Mol Liq 296:111850. https://doi.org/10.1016/j.molliq.2019.111850

Gupta H, Gogate PR (2016) Intensified removal of copper from waste water using activated watermelon based biosorbent in the presence of ultrasound. Ultrason Sonochem 30:113-122. https://doi.org/10. 1016/j.ultsonch.2015.11.016

Hai FI, Yamamoto K, Fukushi K (2007) Hybrid treatment systems for dye wastewater, critical reviews. Environ Sci Technol 37:315-377. https://doi.org/10.1080/10643380601174723

Hameed BH, Salman JM, Ahmad AL (2009) Adsorption isotherm and kinetic modeling of 2,4-D pesticide on activated carbon derived from date stones. J Hazard Mater 163:121-126. https://doi.org/10. 1016/j.jhazmat.2008.06.069

Hassan SS, El-Shafie AS, Zaher N, El-Azazy M (2020) Application of pineapple leaves as adsorbents for removal of rose bengal from wastewater: process optimization operating face-centered central composite design (FCCCD). Molecules 25:3752. https://doi.org/ $10.3390 /$ molecules 25163752

Husein DZ, Aazam E, Battia M (2017) Adsorption of cadmium (II) onto watermelon rind under microwave radiation and application into surface water from Jeddah, Saudi Arabia. Arab J Sci Eng 42: 2403-2415. https://doi.org/10.1007/s13369-016-2381-2

IARC (1978) Acridine orange: IARC monographs on the evaluation of carcinogenic risk of chemicals to man. 16:145-152. https://doi.org/ 10.1101/pdb.caut130. (accessed on 24 March 2020).

Iessi E, Logozzi M, Lugini L, Azzarito T, Federici C, Spugnini EP, Mizzoni D, Di Raimo R, Angelini DF, Battistini L, Cecchetti S, Fais S (2017) Acridine orange/exosomes increase the delivery and the effectiveness of acridine orange in human melanoma cells: a new 
prototype for theranostics of tumors. J Enzyme Inhib Med Chem 32: 648-657. https://doi.org/10.1080/14756366.2017.1292263

Jawad AH, Ngoh YS, Radzun KA (2018) Utilization of watermelon (Citrullus lanatus) rinds as a natural low-cost biosorbent for adsorption of methylene blue: kinetic, equilibrium and thermodynamic studies thermodynamic studies. J Taibah Univ SCI 12:371-381. https://doi.org/10.1080/16583655.2018.1476206

Jawad AH, Razuan R, Appaturi JN, Wilson LD (2019) Adsorption and mechanism study for methylene blue dye removal with carbonized watermelon (Citrullus lanatus) rind prepared via one-step liquid phase $\mathrm{H}_{2} \mathrm{SO}_{4}$ activation. Surf Interfaces 16:76-84. https://doi.org/ 10.1016/j.surfin.2019.04.012

Kant R (2012) Textile dyeing industry an environmental hazard. Nat Sci 4:20-26. https://doi.org/10.4236/ns.2012.41004

Karmakar A, Banerjee S, Singh B, Mandal NC (2019) Study of hydrogen bonding interaction of acridine orange with different acceptor molecules by spectroscopic, theoretical, and antimicrobial studies. J Mol Struct 1177:418-429. https://doi.org/10.1016/j.molstruc.2018.09. 074

Lakshmipathy R, Sarada NC (2013) Application of watermelon rind as sorbent for removal of nickel and cobalt from aqueous solution. Int $\mathrm{J}$ Miner Process 122:63-65. https://doi.org/10.1016/j.minpro.2013. 03.002

Lakshmipathy R, Sarada NC (2015) Biosorptive removal of methylene blue from aqueous solution by chemically activated watermelon rind as adsorbent. J Indian Chem Soc 92:999-1002

Langmuir I (1918) Adsorption of gases on glass, mica and platinum. J Am Chem Soc 40:1361-1403

Li H, Xiong J, Xiao T, Long J, Wang Q, Li K, Liu X, Zhang G, Zhang H (2019) Biochar derived from watermelon rinds as regenerable adsorbent for efficient removal of thallium(I) from wastewater. Process Saf Environ Prot 127:257-266. https://doi.org/10.1016/j.psep.2019. 04.031

Liu J, Yang H, Gosling SN, Kummu M, Flörke M, Pfister S, Hanasaki N, Wada Y, Zhang X, Zheng C, Alcamo J, Oki T (2017) Water scarcity assessments in the past, present, and future. Earth's Future 5:545559. https://doi.org/10.1002/2016EF000518

López-velandia C, Moreno-barbosa JJ, Sierra-ramirez R (2014) Adsorption of volatile carboxylic acids on activated carbon synthesized from watermelon shells. Adsorpt Sci Technol 23:227-242. https://doi.org/10.1260/0263-6174.32.2-3.227

Masoudian N, Rajabi M, Ghaedi M (2019) Titanium oxide nanoparticles loaded onto activated carbon prepared from bio-waste watermelon rind for the efficient ultrasonic-assisted adsorption of Congo red and phenol red dyes from wastewaters. Polyhedron 173:114105. https:// doi.org/10.1016/j.poly.2019.114105

Mekonnen MM, Hoekstra AY (2016) Four billion people facing severe water scarcity. Sci Adv 2:1-6. https://doi.org/10.1126/sciadv. 1500323
Memon GZ, Bhanger MI, Akhtar M, Talpur FN, Memon JR (2008) Adsorption of methyl parathion pesticide from water using watermelon peels as a low cost adsorbent. Chem Eng J 138:616-621. https://doi.org/10.1016/j.cej.2007.09.027

Montes-Atenas G, Valenzuela, F (2017) Wastewater treatment through low cost adsorption technologies. In: Farooq R (ed) Ahmad Z Physico-Chemical Wastewater Treatment and Resource Recovery. IntechOpen, DOI: https://doi.org/10.5772/67097. Available from: https://www.intechopen.com/books/physico-chemical-wastewatertreatment-and-resource-recovery/wastewater-treatment-throughlow-cost-adsorption-technologies

Moussavi G, Barikbin B (2010) Biosorption of chromium (VI) from industrial wastewater onto pistachio hull waste biomass. Chem Eng J 162:893-900. https://doi.org/10.1016/j.cej.2010.06.032

Oladipo A, Gazi M, Yilmaz E (2015) Single and binary adsorption of azo and anthraquinone dyes by chitosan-based hydrogel: selectivity factor and Box-Behnken process design. Chem Eng Res Des 104:264 279. https://doi.org/10.1016/j.cherd.2015.08.018

Prasad AL, Santhi T (2012) Adsorption of hazardous cationic dyes from aqueous solution onto Acacia nilotica leaves as an eco-friendly adsorbent. Sustain Environ Res 22:113-122

Reddy NA, Lakshmipathy R, Sarada NC (2014) Application of Citrullus lanatus rind as biosorbent for removal of trivalent chromium from aqueous solution. Alex Eng J 53:969-975. https://doi.org/10.1016/j. aej.2014.07.006

Rouqueroltd J, Avnir D, Fairbridge CW, Everett DH, Haynes JH, Pernicone N, Ramsay JDF, Sing KSW, Unger KK (1994) Recommendations for the characterization of porous solids. Pure Appl Chem 66:1739-1758

Sharma AS, Ilanchelian M (2014) Elucidation of photophysical changes and orientation of acridine orange dye on the surface of borate capped gold nanoparticles by multi spectroscopic techniques. Photochem Photobiol Sci 13:1741-1752

Singh T, Singhal R (2015) Methyl Orange adsorption by reuse of a waste adsorbent poly(AAc/AM/SH)-MB superabsorbent hydrogel: matrix effects, adsorption thermodynamic and kinetics studies. Desalination Water Treat 53(7):1942-1956

Stankovich S, Dikin DA, Piner RD, Kohlhaas KA, Kleinhammes A, Jia Y, Wu Y, Nguyen SB, Ruoff RS (2007) Synthesis of graphenebased nanosheets via chemical reduction of exfoliated graphite oxide. Carbon 45:1558-1565. https://doi.org/10.1016/j.carbon.2007. 02.034

Verma AK, Dash RR, Bhunia P (2012) A review on chemical coagulation/flocculation technologies for removal of colour from textile wastewaters. J Environ Manag 93:154-168. https://doi.org/ 10.1016/j.jenvman.2011.09.012

Publisher's note Springer Nature remains neutral with regard to jurisdictional claims in published maps and institutional affiliations. 